\title{
DIGITAL CONNECTIVITY AND LOW EARTH ORBIT SATELLITE CONSTELLATIONS OPPORTUNITIES FOR ASIA AND THE PACIFIC
}

John Garrity and Arndt Husar

NO. 76

April 2021

\section{ADB SUSTAINABLE DEVELOPMENT WORKING PAPER SERIES}





\section{ADB Sustainable Development Working Paper Series}

\section{Digital Connectivity and Low Earth Orbit Satellite Constellations: Opportunities for Asia and the Pacific}

John Garrity and Arndt Husar

No.76 | April 2021
John Garrity is an economist, policy advisor, and project manager focusing on digital inclusion, universal internet access policy, and last-mile connectivity. He has previously held positions at the United States Agency for International Development, Cisco Systems, and World Bank and is currently a consultant for a number of organizations, including the Asian Development Bank (ADB), International Telecommunication Union, United Nations Development Programme (UNDP), Broadband Commission, UN Economic and Social Commission for Asia and the Pacific, and Connectivity Capital, among others. He has coauthored numerous reports on technology and development and has presented around the world on efforts to close the digital divide.

Arndt Husar facilitates the effective use of digital technology, advising ADB clients, regional departments, as well as sector and thematic groups on digital transformation. He is a senior public management specialist (digital transformation) in ADB's Digital Technology for Development Unit and serves as a member of the Innovation Task Force, supporting the bank's futures thinking and foresight activities. He has over 16 years of professional experience in the development sector, focusing on governance, public sector reform, start-up ecosystems, and urban development. Prior to ADB he worked with the UNDP at national, regional, and global levels. 
(C) 2021 Asian Development Bank

6 ADB Avenue, Mandaluyong City, 1550 Metro Manila, Philippines

Tel +632 8632 4444; Fax +63286362444

www.adb.org

Some rights reserved. Published in 2021.

Publication Stock No. WPS210156-2

DOI: http://dx.doi.org/10.22617/WPS210156-2

The views expressed in this publication are those of the authors and do not necessarily reflect the views and policies of the Asian Development Bank (ADB) or its Board of Governors or the governments they represent.

ADB does not guarantee the accuracy of the data included in this publication and accepts no responsibility for any consequence of their use. The mention of specific companies or products of manufacturers does not imply that they are endorsed or recommended by ADB in preference to others of a similar nature that are not mentioned.

By making any designation of or reference to a particular territory or geographic area, or by using the term "country" in this document, $A D B$ does not intend to make any judgments as to the legal or other status of any territory or area.

This work is available under the Creative Commons Attribution 3.0 IGO license (CC BY 3.0 IGO)

https://creativecommons.org/licenses/by/3.0/igo/. By using the content of this publication, you agree to be bound by the terms of this license. For attribution, translations, adaptations, and permissions, please read the provisions and terms of use at https://www.adb.org/terms-use\#openaccess.

This CC license does not apply to non-ADB copyright materials in this publication. If the material is attributed to another source, please contact the copyright owner or publisher of that source for permission to reproduce it. ADB cannot be held liable for any claims that arise as a result of your use of the material.

Please contact pubsmarketing@adb.org if you have questions or comments with respect to content, or if you wish to obtain copyright permission for your intended use that does not fall within these terms, or for permission to use the ADB logo.

The ADB Sustainable Development Working Paper Series presents data, information, and/or findings from ongoing research and studies to encourage exchange of ideas and elicit comment and feedback about development issues in Asia and the Pacific. Since papers in this series are intended for quick and easy dissemination, the content may or may not be fully edited and may later be modified for final publication.

Corrigenda to ADB publications may be found at http://www.adb.org/publications/corrigenda.

Notes:

In this publication, “\$” refers to United States dollars.

Data regarding satellites in orbit are correct as of 7 April 2021.

ADB recognizes "China" as the People's Republic of China and "Russia" as the Russian Federation. 


\section{CONTENTS}

TABLES AND FIGURES iv

ACKNOWLEDGMENTS v v

ABBREVIATIONS vi

WEIGHTS AND MEASURES Nii

EXECUTIVE SUMMARY viii

$\begin{array}{ll}\text { I. INTRODUCTION } & 1\end{array}$

II. BACKGROUND: SATELLITE CONNECTIVITY AS A MEANS 1 FOR BROADBAND INTERNET

III. INNOVATION IN LOW EARTH ORBIT SATELLITE CONSTELLATIONS 7

IV. IN FOCUS: STARLINK'S DEPLOYMENT, DIFFERENTIATION, AND VIABILITY 22

V. OPPORTUNITIES AND BARRIERS TO LEVERAGING LOW EARTH ORBIT 23 SATELLITES IN DEVELOPING MEMBER COUNTRIES

VI. RECOMMENDATIONS: WHAT DEVELOPING MEMBER COUNTRIES 28 CAN DO TO LEVERAGE THE OPPORTUNITY PRESENTED BY LOW EARTH ORBIT SATELLITES 


\section{TABLES AND FIGURES}

\section{TABLES}

1 Three Communication Satellite Constellations That Have Been Operating in Low Earth Orbit

2 Sample Retail Satellite Service Offerings (Advertised Maximum Speeds, Not Dedicated or Committed Throughput)

3 Differences in Deployments, Constellations, and Satellites 16

4 Recent National Satellite Deployments in Asia 25

5 Differences in Licensing Requirements for Internet Service Providers 27 across Asia and the Pacific

\section{FIGURES}

1 Percentage of Individuals Using the Internet by Region and Development Status, 2019

2 Internet Infrastructure Network 4

3 Technologies Compared by Costs and Population Density 5

4 Price Optimization for Satellite Backhaul and Crossover Point 6

5 Comparison of Characteristics: Geostationary Orbit, Medium Earth Orbit, 10 and Low Earth Orbit

6 Total Sellable Satellite Bandwidth Capacity, 2019-2025 11

7 Asia Total Bandwidth Demand 11

8 Differences in Per-Satellite Data Rates 17

9 SpaceX Launch Pricing $\quad 20$

10 SpaceX StarShip Compared to Renders of Falcon 9 and Dragon Payloads 21

11 Bandwidth Demand by Application for Geostationary Orbit 24 High-Throughput Satellites in Asia and the Pacific

12 Overall Shares of the High-Throughput Satellites Market Supplied 24 by Non-Geostationary Orbit (Medium Earth Orbit and Low Earth Orbit) Satellites

13 Space Segment Cost Benchmark Comparisons 


\section{ACKNOWLEDGMENTS}

This paper was prepared as part of the implementation of the Asian Development Bank (ADB) regional technical assistance, Digital Development Facility for Asia and the Pacific project, which is cofinanced by the Republic of Korea e-Asia and Knowledge Partnership Fund. John Garrity, domain expert and digital connectivity consultant, ADB and Arndt Husar, senior public management specialist (digital transformation), ADB Sustainable Development and Climate Change Department (SDCC) led the development of the working paper, with overall direction from Thomas Abell, chief, Digital Technology for Development Unit, SDCC. In researching this working paper, interviews were conducted for background context with a range of industry experts, in addition to accessing publicly available documents, including research reports, media articles, academic papers, webinars, and videos. ADB would like to thank all those who have shared their expertise with us in this process.

Juliette Leusink, senior investment officer, Office for Public-Private Partnership, provided useful inputs and feedback. Monina Macaraig-Gamboa, consultant, ADB copyedited the draft paper and Lawrence Casiraya, consultant, ADB proofread the draft paper. Alvin Tubio, consultant, ADB typeset the final publication. Laarni Zapanta-Tuazon, senior operations assistant, SDCC and Carmela Fernando-Villamar, digital technology officer, SDCC provided valuable administrative support.

The peer reviewers of this working paper were Antonio García-Zaballos, telecom lead specialist, Inter-American Development Bank and Xavier Lobao, head, Future Projects Division, Telecommunications and Integrated Applications Directorate, European Space Agency. We are most grateful for their feedback and advice.

ADB greatly acknowledges all these contributions and would like to give special thanks to colleagues at the International Telecommunications Union (ITU) Regional Office for Asia and the Pacific, with whom we are collaborating closely to advance digital connectivity in the region. Atsuko Okuda, regional director, ITU Regional Office for Asia and the Pacific; S. Ismail Shah, ITU representative for Southeast Asia, Timor-Leste, and other member states in Asia and the Pacific; Aamir Riaz and Sean Doral, ITU program officers; and Rury Demsey, ITU junior professional officer, who all provided valuable feedback and inputs. 


\section{ABBREVIATIONS}

$\begin{array}{ll}\text { ADB } & \text { Asian Development Bank } \\ \text { CAPEX } & \text { capital expenditure } \\ \text { DMC } & \text { developing member country } \\ \text { FCC } & \text { Federal Communications Commission } \\ \text { GEO } & \text { geostationary orbit } \\ \text { HTS } & \text { high-throughput satellite } \\ \text { ICT } & \text { information and communications technology } \\ \text { ISS } & \text { International Space Station } \\ \text { ITU } & \text { International Telecommunication Union } \\ \text { LEO } & \text { low Earth orbit } \\ \text { MEO } & \text { medium Earth orbit } \\ \text { NASA } & \text { National Aeronautics and Space Administration } \\ \text { NGSO } & \text { non-geostationary orbit } \\ \text { OISL } & \text { optical inter-satellite link } \\ \text { US } & \text { United States } \\ \text { VSAT } & \text { very small aperture terminal } \\ \text { Wi-Fi } & \text { wireless fidelity }\end{array}$




\section{WEIGHTS AND MEASURES}

$\begin{array}{ll}\text { Gbps } & \text { gigabits per second } \\ \mathrm{km} & \text { kilometer } \\ \text { Mbps } & \text { megabits per second } \\ \text { Tbps } & \text { terabits per second }\end{array}$




\section{EXECUTIVE SUMMARY}

Satellite communication plays a necessary role in the global connectivity ecosystem, connecting rural and remote populations, providing backhaul connectivity to mobile cellular networks, and rapidly establishing communication in emergency and disaster response scenarios. This Asian Development Bank (ADB) Sustainable Development Working Paper, the first in a series reviewing emerging innovations in connectivity technologies, focuses on low Earth orbit (LEO) satellites, which have been in deployment for decades and are again a subject of intensive investment as new large constellations are in early stages of deployment. These new LEO constellations, such as those being deployed by Starlink by SpaceX, Project Kuiper by Amazon, OneWeb, Lightspeed by Telesat, among others, may prove to be transformational to the connectivity landscape based on their global coverage and their suitability for areas not served by fiber optic cable networks.

ADB's developing member countries are well placed to leverage and benefit from this expansion of internet connectivity, particularly for underserved geographies and countries with limited international internet bandwidth, such as landlocked developing countries and small island developing states. With their global reach and coverage, LEO constellations are expected to dramatically expand the availability of high-speed broadband internet access with levels of service that rival fiber optic cables in terms of speed and latency, and at significantly reduced price levels compared to traditional geostationary satellites.

A proactive engagement with LEO solutions is likely to yield benefits as the relevant business models are still evolving. Well-informed early action by regulators and investors can ensure that developing member countries prepare for opportunities presented by the anticipated expansion of connectivity bandwidth. 


\section{INTRODUCTION}

This Emerging Connectivity Innovations Case Study on SpaceX Starlink and low Earth orbit (LEO) satellite constellations is intended to provide readers, particularly in developing countries in Asia and the Pacific, with a background understanding of the role of satellite communications in global internet connectivity and an exploration of the potential impact of the next generation of LEO constellation systems.

While the adoption of internet connectivity across the world has generally increased incrementally, some innovations have been transformational, dramatically expanding the geographic reach of connectivity and bandwidth capacity. For example, the introduction of basic mobile phones in the late 1990s and early 2000s led to rapid adoption of mobile telephony across low- and middle-income countries (a phenomenon known as the "mobile miracle"). Similarly, public and private investment in undersea fiber optic cables circling sub-Saharan Africa in the 2000s significantly reduced the cost of bandwidth in many countries in the region.

Satellites have used low Earth orbits since the beginning of space exploration; however, private investment in LEO constellations, consisting of hundreds or thousands of satellites, has been limited because significant up-front capital expenditure is required. While it remains to be seen how the next generation of LEO satellite constellations will evolve, LEOs are forecasted to significantly increase the available internet bandwidth in remote and rural geographies not currently served by fiber optic cables. This increased bandwidth could be leveraged to increase economic and social development opportunities for individuals, organizations, businesses, and government facilities (including public schools) located in these areas, provided that the private sector satellite companies investing in LEO constellations see market opportunities to extend service to these areas. This case study is intended to introduce to Asian Development Bank developing member countries how to start preparing for the expansion of LEO satellite communication services.

\section{BACKGROUND: SATELLITE CONNECTIVITY AS A MEANS FOR BROADBAND INTERNET}

\section{Internet connectivity has become a necessary component of every country's critical infrastructure given the reliance of all aspects of economic activity, governance, and social development on internet communications.}

The coronavirus disease (COVID-19) pandemic dramatically increased the importance of internet communications infrastructure. Trade, employment, learning, leisure, and communications quickly shifted into the digital sphere and countries with robust internet infrastructure and high adoption rates of internet-enabled devices were better able to adjust and adapt to the shift to digital activity. The United Nations estimates that 1.6 billion learners were affected by school closures in 2020, affecting $94 \%$ of the world's student population and up to $99 \%$ in low and lower middle-income countries. ${ }^{1}$

United Nations. 2020. Policy Brief: Education during COVID-10 and beyond. 
Access to distance learning opportunities varies greatly by country and income groups, with estimates of less than half of students in low-income countries able to access distance learning. ${ }^{2}$

Internet access and adoption in the developing member countries (DMCs) of the Asian Development Bank (ADB) continues to grow, particularly as a result of public and private investment in telecommunications infrastructure, increased competition, and allocation of shared resources, such as spectrum auctions and assignment. Despite these efforts, large access gaps remain in Asia, where the most remote, difficult to reach, or sparsely populated districts remain disconnected, leaving more than half of the population without access to the internet. This lack of digital infrastructure represents a missed opportunity to accelerate economic and social development.

\section{Despite the rapid expansion of internet connectivity infrastructure across the world, significant gaps in internet adoption and infrastructure access remain. This highlights the importance of satellite communications that can bridge gaps, swiftly expand network coverage, and enhance existing infrastructure.}

The latest estimates from the International Telecommunication Union (ITU) show that 3.7 billion people are still not participating online (49\% of the global population), and $63 \%$ of rural households are without internet access (Figure 1). ${ }^{3}$ Also, 1.5 billion people reside in areas without high-speed mobile data coverage (fourth generation long-term evolution or 4G LTE), while 607 million people reside in areas with no mobile data coverage at all (at least 4G or third generation [3G] coverage). Furthermore, 313 million people reside in areas with only basic voice and short messaging service (SMS) coverage (second generation [2G]), and 220 million people reside in areas with no cellular coverage. The ITU estimates that nearly $\$ 428$ billion is required to achieve universal access to broadband globally, $\$ 251$ billion of which is required for Asia, with approximately 75\% coming from the private sector and the remainder with support from the public sector. ${ }^{4}$

The majority of the world's population, over 5 billion people, live more than 10 kilometers (km) away from any fiber optic cable infrastructure ( 3.6 billion reside more than $25 \mathrm{~km}$ away). ${ }^{5}$ Other issues, such as affordability, digital literacy, and the lack of relevant or local language content, have resulted in 2.4 billion people who live within $4 \mathrm{G}$ coverage not subscribing to $4 \mathrm{G}$ data services.

2 See, for instance, the report by the Inter-American Development Bank (IDB) estimating the dampening effect of gross domestic product (GDP) losses because of countries' ability to implement telework and distance learning. IDB. 2020. The Impact of Digital Infrastructure on the Consequences of COVID-19 and on the Mitigation of Future Effects.

3 International Telecommunication Union (ITU). 2020. Measuring Digital Development: Facts and Figures 2020.

$4 \quad$ ITU. 2020. Connecting Humanity.

$5 \quad$ ITU and UNESCO. 2019. The State of Broadband 2019: Broadband as a Foundation for Sustainable Development. 
Figure 1: Percentage of Individuals Using the Internet by Region and Development Status, 2019

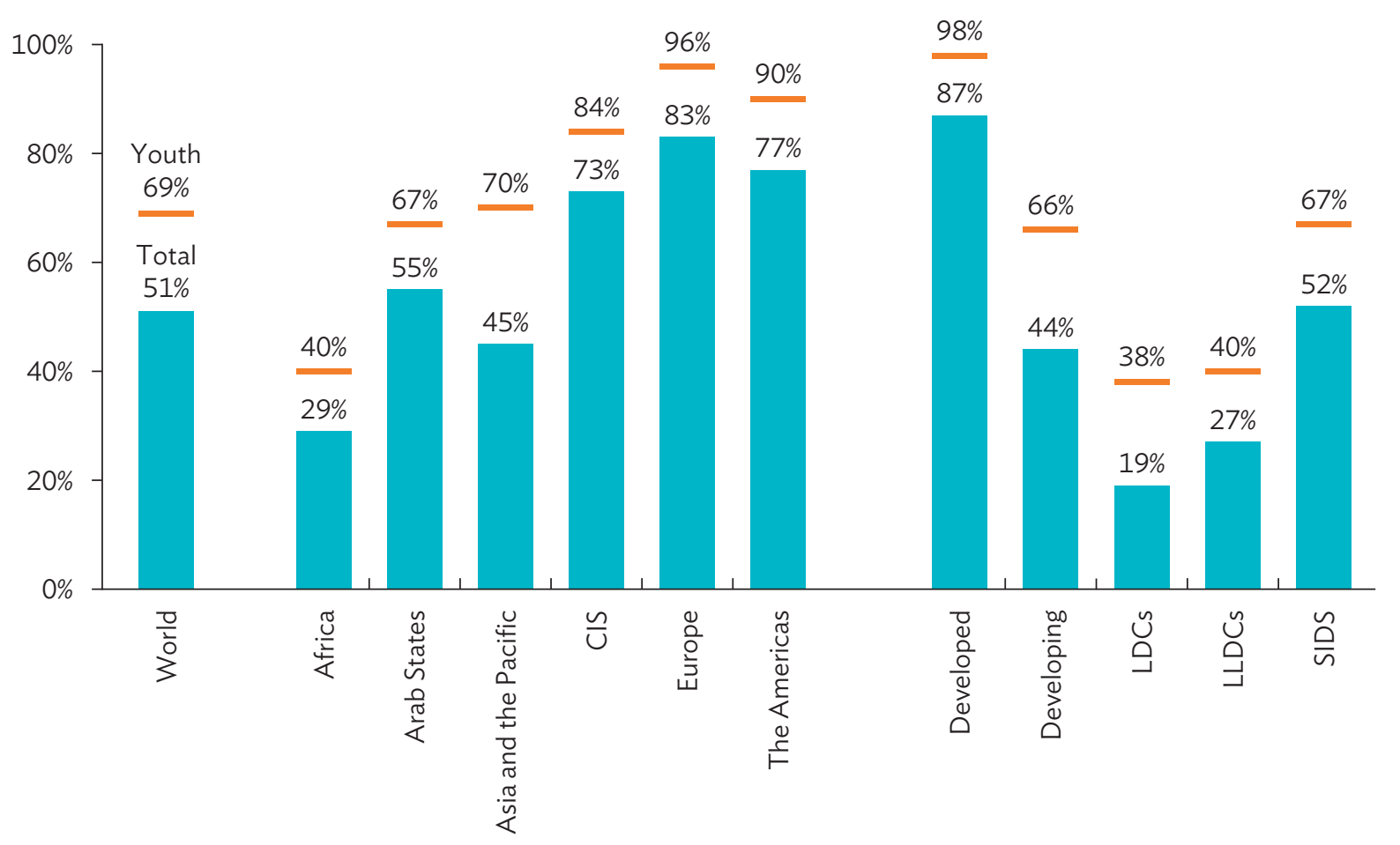

$\mathrm{CIS}=$ Commonwealth of Independent States, LDC = least developed country, LLDC = landlocked developing country, SIDS = small island developing state.

Note: Youth means individuals 15-24 years old using the internet as a percentage of the total population.

Source: International Telecommunication Union. 2020. The Last-Mile Internet Connectivity Solutions Guide: Sustainable Connectivity Options for Unconnected Sites.

\section{Satellite connectivity is predominantly used for backhaul connectivity for remote cellular base stations and as a last-mile connection for individual subscribers and enterprises.}

Figure 2 provides an overview of the internet infrastructure network components, from international connectivity to the last mile. Because of the higher relative cost of bandwidth transmitted via satellite versus terrestrial technologies, satellite is currently primarily used in situations where fiber optic cables and other high-capacity technologies are not financially viable due to low population densities and large distances between high-capacity networks and last-mile networks. ${ }^{6}$ However, in a few cases, satellite connectivity is relied upon for international internet gateway traffic or as part of a country's core network. For landlocked developing countries that are dependent on terrestrial fiber connectivity, in some cases, satellite connectivity serves as a substitute to complex bilateral and multilateral negotiations to extend costly fiber connectivity to their country.

$6 \quad$ In the case of Pacific island countries, satellite connectivity is increasingly playing a complementary role to undersea fiber optic cable deployment, including as a redundancy option. UNESCAP. 2019. Satellite Communications in Pacific Island Countries. 


\section{Figure 2: Internet Infrastructure Network}

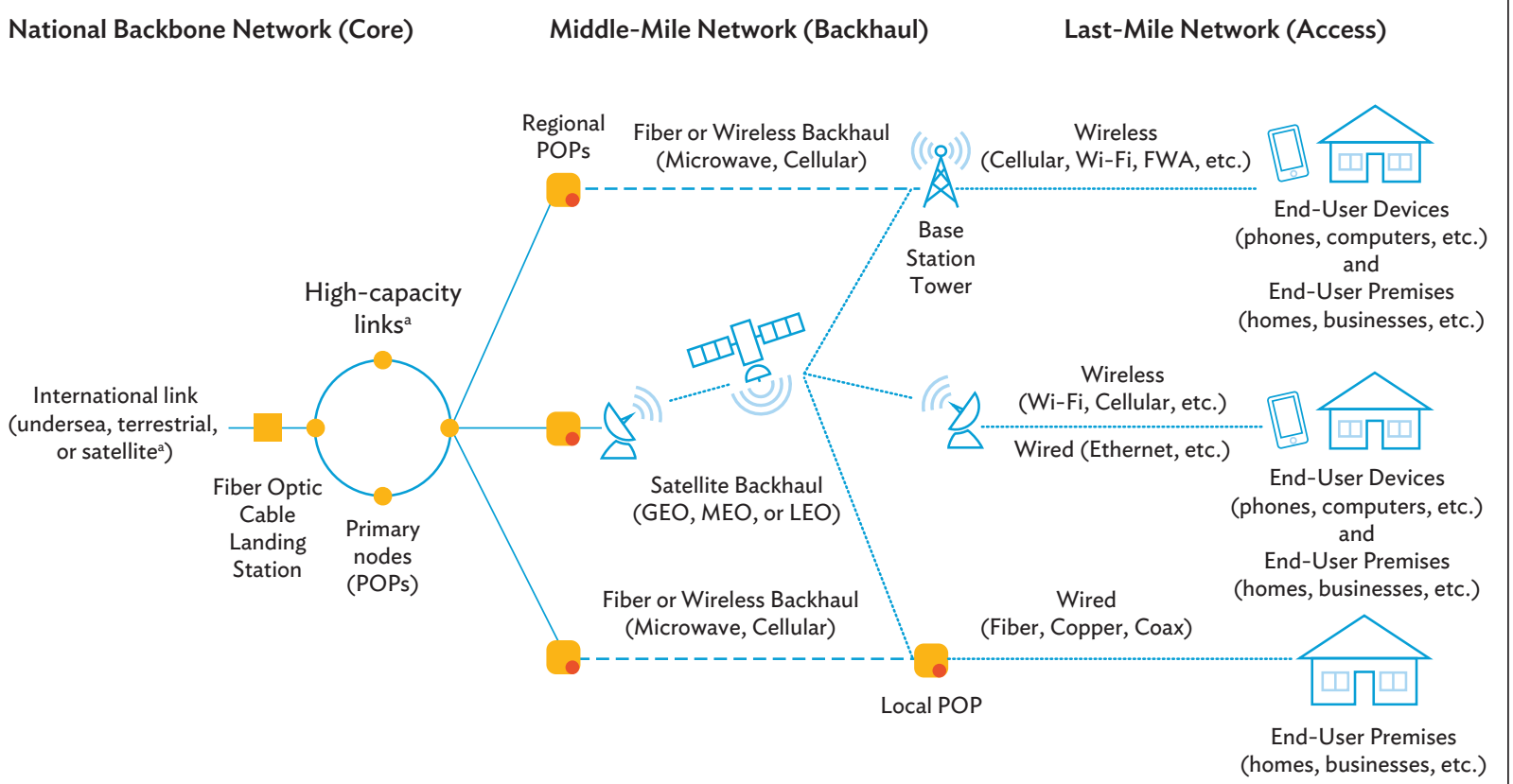

FWA = fixed wireless access, $\mathrm{GEO}=$ geostationary orbit, $\mathrm{LEO}=$ lower Earth orbit, $\mathrm{MEO}=$ medium Earth orbit, $\mathrm{POP}=$ point of presence, $\mathrm{Wi}-\mathrm{Fi}=$ wireless fidelity.

Notes: Shaded area depicts where satellite connectivity is used. Not exhaustive, for illustrative purposes, and some segments are interchangeable further, particularly in the last mile.

a In few country cases, satellite continues to be the main or only source of international connectivity.

b These are predominantly fiber-optic links (terrestrial and undersea), but in the case of a few countries, national backbone networks use wireless microwave and satellite.

Source: International Telecommunication Union. 2020. The Last-Mile Internet Connectivity Solutions Guide: Sustainable Connectivity Options for Unconnected Sites.

\section{Satellite connectivity provides global coverage, with trade-offs in capacity and affordability.}

Satellite communications coverage is already global, composed of geostationary orbit (GEO) satellites (also known as geostationary Earth orbit), medium Earth orbit (MEO), and low Earth orbit (LEO) constellations. ${ }^{7}$ (See Chapter 1, Figure 5 for differences between LEO, MEO, and GEO.) There are currently at least 775 active satellites in orbit that serve primary communications functions (excluding the new LEO constellations). ${ }^{8}$ However, the total satellite sellable capacity in 2020 of approximately 3 terabits per second (Tbps) is dwarfed by the roughly 2,000 Tbps of utilized terrestrial fiber capacity, ${ }^{9}$

7 Low Earth orbit (LEO) and medium Earth orbit (MEO) satellites are often grouped together as non-geosynchronous orbit (NGSO).

$8 \quad$ ITU/UNESCO. 2020; and SatBeams. 2020. List of Satellites at Geostationary Orbit.

$9 \quad$ A. Mauldin. 2019. Will New Satellites End the Dominance of Submarine Cables. Telegeography Blog. 1 July. 
which still is only a fraction of the total potential capacity on existing cables (international internet capacity). As of early 2020, there were at least 406 submarine cables in service and $99 \%$ of total international internet data traffic is transmitted via fiber optic cables. ${ }^{10}$ Wholesale prices also differ dramatically with international internet transit (IP transit) pricing as low as $\$ 1-\$ 3$ per megabit per second (Mbps) per month on major cross-country routes against wholesale prices for dedicated satellite capacity approaching $\$ 200-\$ 400$ Mbps per month..$^{11}$ Therefore, satellite connectivity is only costcompetitive for remote and dispersed populations where fiber deployments are challenging. The new generation of LEO and high-throughput GEO satellites are expected to lower the cost structure and make satellite connectivity more competitive (Figure 3).

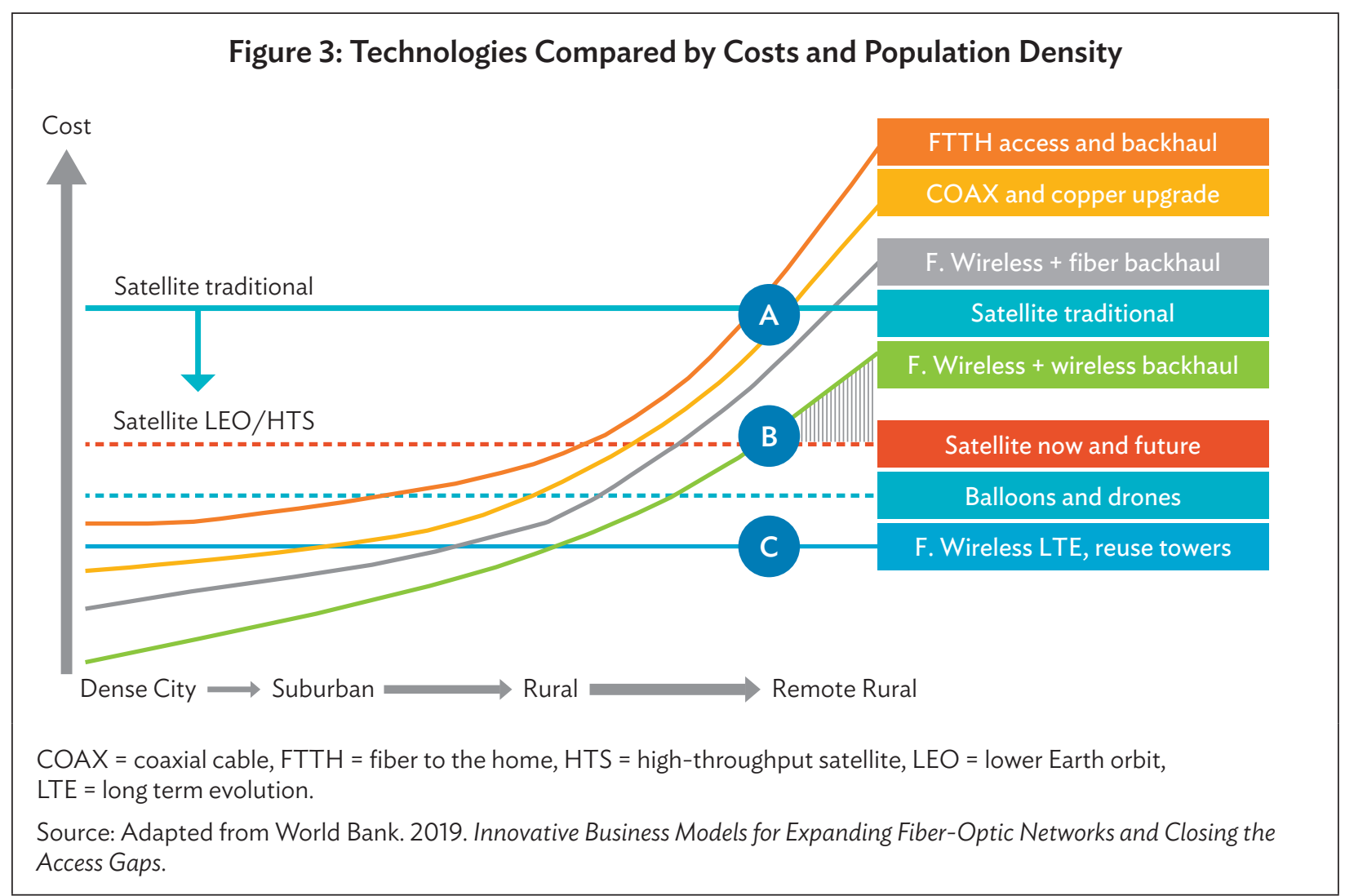

Particularly in situations where a high degree of data throughput is required per site, such as satellite backhaul for broadband cellular networks, the data volumes as well as the distance to the nearest backbone node play a significant role in cost comparisons between satellite connectivity versus terrestrial

10 Telegeography Blog. 2020. Submarine Cable 101; The preference for submarine cable traffic is also due to latency requirements, such as for financial transactions. This may be expected to change as LEO demonstrates fiber-like latency (or better).

11 Satellite Signals. 2020. Internet VSAT Access Via Satellite: Costs; J. Del Rosario. 2017. Pricing the Satellite Markets. National Sky Research. 22 August; Aid and International Development Forum. 2019. Ka vs. Ku Band: Which is the Best for Satellite Broadband? 24 September; Telegeography. 2020. Global IP Transit Prices Keep Doing What They Do Best. 
network deployments (microwave backhaul, in particular). Figure 4 illustrates how higher data bandwidth requirements are more cost-effectively supplied by terrestrial ground networks; however, a crossover point occurs where satellite capacity may end up being more cost-competitive, depending on different price points of satellite bandwidth and total traffic demand per month. ${ }^{12}$ Satellite connectivity is also wellsuited to deploy in emergency situations, such as in response to natural disasters or other external shocks, that require expeditious deployment of network connectivity where terrestrial infrastructure is either nonexistent or destroyed.

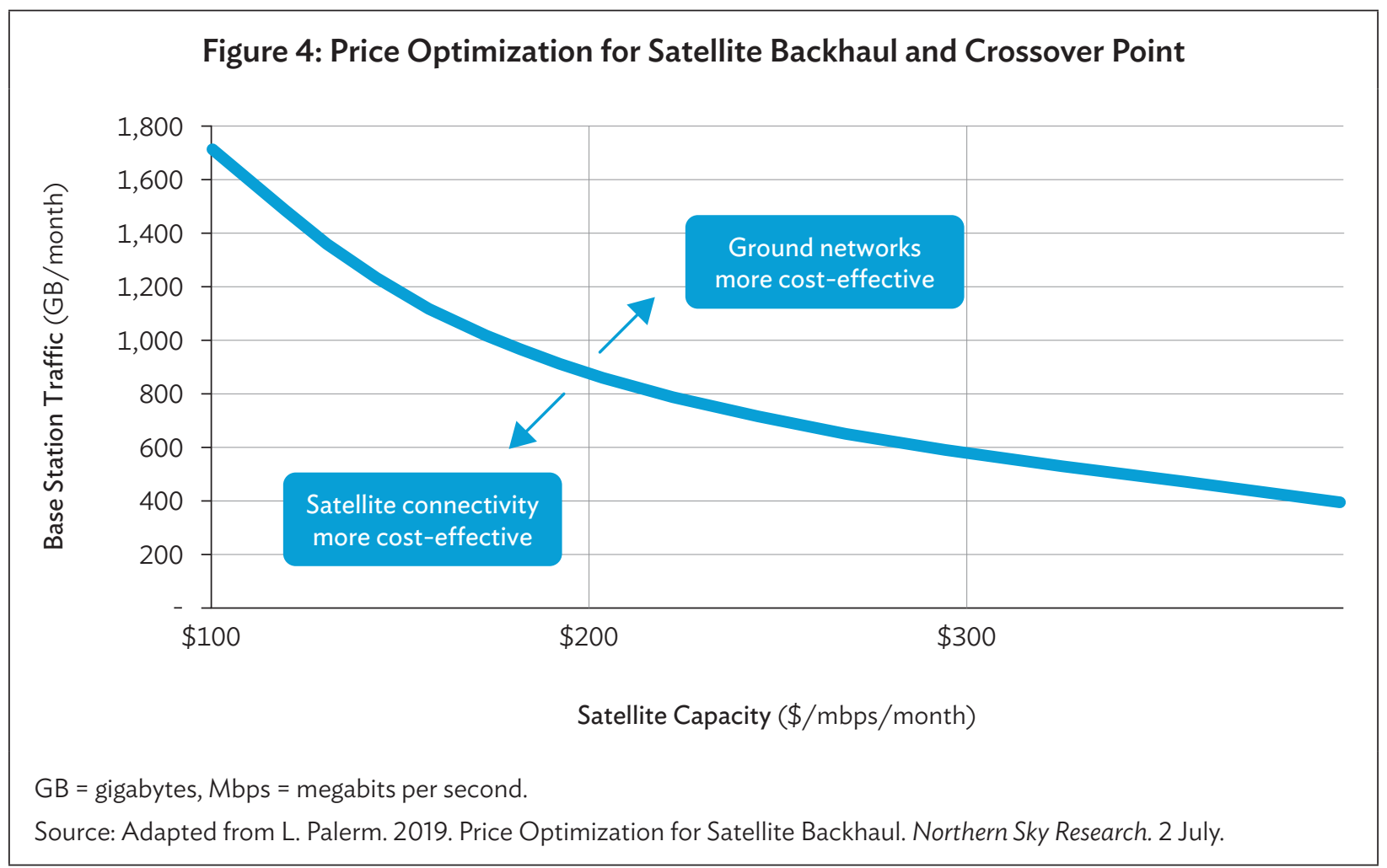

For many rural and remote communities, satellites are the only connectivity option.

For geographies without direct access to fiber optic cable infrastructure or at great distances from highcapacity bandwidth capacity, satellite connectivity is the only option available. Even where terrestrial network infrastructure that could be used for backhaul connectivity is available, satellite deployments may still be preferred because satellite terminals require only electrical power and a clear line of sight to the sky. However, an expansion of terrestrial infrastructure usually requires extensive civil works (underground fiber ducts, pole attachments, or tower construction for cellular base stations), which comes with challenges such as securing the rights-of-way, permits, and having to pay the related fees.

12 L. Palerm. 2019. Price Optimization for Satellite Backhaul. Northern Sky Research. 2 July. 


\title{
Satellite broadband is poised to become an even more important technology for addressing the growing digital divide.
}

As information and communication technologies play an increasingly important role in commerce, government services, health care, education, and other sectors, satellite connectivity allows communities to get connected swiftly, bypassing the infrastructure deployment challenges that come with terrestrial infrastructure deployments. The role of satellite connectivity in emergency telecommunications has also been vital where the communications satellites are heavily relied upon in disaster recovery efforts. ${ }^{13}$ Satellite technology may also be complementary with traditional wired and mobile broadband, which are better suited for densely populated areas. Satellite service could become a default solution for remote areas, allowing terrestrial services to focus on improving access in their current coverage areas. Satellite connectivity is already being used for network redundancy at national levels for international internet capacity, as well as for backup in core and backhaul networks. ${ }^{14}$

The recent $\$ 50$ million loan to Kacific by ADB for the deployment of a broadband satellite, which covers large parts of Southeast Asia and the Pacific, demonstrates the relevance of satellite connectivity for unserved and underserved regions. ${ }^{15}$ By deploying new satellite technology (in the Ka-band ${ }^{16}$ ), Kacific's service offering is commercially viable despite the existing presence of other major competitors in Asia and the Pacific, including global entities such as Intelsat, SES, and Eutelsat, as well as more regional players such as AsiaSat, Thaicom, MEASAT, and SKY Perfect JSAT.

\section{INNOVATION IN LOW EARTH ORBIT SATELLITE CONSTELLATIONS}

\author{
Low Earth orbit satellites have been a feature of space satellites since the beginning of \\ space exploration.
}

Since the start of space exploration, low Earth orbits between 160-2,000 km above the Earth's surface have been used for satellite placement. For example, Earth observation, spy, and remote sensing satellites have been using low Earth orbits to obtain high-resolution measurements of the Earth's surface.

13 ITU. 2020. ITU and Kacific Join Forces to Boost Emergency Telecoms and ICT Development in Vanuatu. ITU News. 19 May.

14 See, for instance, the 2016 Inter-American Development Bank report on "The Provision of Satellite Broadband Services in Latin America and the Caribbean."

15 ADB. 2019. Kacific1 Satellite Launch to Bring Affordable Internet to Remote Parts of Asia and Pacific. News release. 17 December.

16 Use of the Ka-band of radio spectrum frequencies, in the 26.5-40 gigahertz $(\mathrm{GHz})$ range is an advancement over use of the Ku-band $(12-18 \mathrm{GHz}$ ) as the higher frequency allows for greater throughput and higher data transfer (and corresponding lower cost per bit transferred). However, interference from water droplets (rain fade, humidity) is an issue in both spectrum bands. 
The International Space Station (ISS) is in a LEO of 400-420 km and is in constant orbital decay, requiring re-boosting a few times a year. The Hubble Space Telescope is also in a LEO position at an altitude of $540 \mathrm{~km}$. Communications satellites that provide satellite phone service use LEOs, for example, Iridium satellites orbit at about $780 \mathrm{~km}$ to limit latency (the round trip time for data to travel between communication points) delays in voice transmissions.

\section{Before the 1990s, low Earth orbits were used only by government satellites for military and scientific missions, but have since become the focus of commercial deployments.}

Large-scale commercial deployments first began in the 1990s, when several companies tried to provide global connectivity, for example, Globalstar, Iridium, Odyssey, and Teledesic. Because individual LEO satellites cover a limited geographic area, constellations need hundreds or thousands of satellites and ground stations to achieve robust global coverage depending on orbital altitude above the Earth's surface. Unfortunately, previous large-scale plans were cancelled or reduced due to high costs and limited demand. Industry analysts have since been skeptical of LEO constellation viability (exemplified by the recent challenges of OneWeb and LeoSat). ${ }^{17}$ Three communication satellite constellations have been operating in LEO since the early 2000s: Iridium, Globalstar, and Orbcomm (Table 1). ${ }^{18}$

\section{Low Earth orbit constellations provide fundamentally different value propositions compared to geostationary orbit.}

GEO satellites are positioned at an altitude of $35,786 \mathrm{~km}$ and, as a result, each satellite has a very wide coverage area. This allows them to focus their bandwidth capacity on their coverage area and reduces the requirement for achieving global coverage to as few as three satellites. However, because of their distance from the Earth's surface, their minimum latency thresholds are high (roughly at least 0.477 seconds for round trip latency).

The latest generation of GEO satellites, known as high-throughput satellites (HTSs), have a significantly increased capacity (at least 10 times the throughput) than previous generations of GEO satellites, while the high latency (which is a function of distance and the speed of light) remains the same. ${ }^{19}$

In comparison, LEO constellations require a network of satellites to provide internet service because each LEO satellite is traversing the Earth's surface, orbiting the planet every 88-127 minutes (depending on their altitude, between $160-2,000 \mathrm{~km}$ ). Their closer distance to the Earth's surface enables them to provide high-speed, low-latency internet. MEO satellites are positioned between LEO and GEO orbits, circling the planet by 2,000-35,786 km. These satellites handle high-speed, low-latency data traffic (particularly cellular backhaul). ${ }^{20}$

17 OneWeb. 2020. OneWeb Files for Chapter 11 Restructuring to Execute Sale Process. 27 March; and A. WainscottSargent. 2019. LEO Advances on the Ground. Via Satellite.

18 Asia-Pacific Satellite Communications Council. 2018. GEO-HTS and NGSO-HTS. APSCC Quarterly Newsletter. 24(4).

19 Note, however, that there are software networking techniques that help to reduce the impact of latency on applications, but do not reduce the latency itself. See for instance, iTrinegy. n.d. Why is Satellite Latency High?

20 Note that High Altitude Platform Systems or HAPS, which go as high as $50 \mathrm{~km}$, may also be feasible solutions in some situations. 
Table 1: Three Communication Satellite Constellations That Have Been Operating in Low Earth Orbit

\begin{tabular}{lccc}
\hline & Iridium & Globalstar & Orbcomm \\
\hline Satcom service & Narrowband (GMPCS) & Narrowband (GMPCS) & Narrowband (low rate data) \\
\hline Satellite fleet in orbit & 70 & 24 & 18 \\
\hline Start of operations & 2001 & 2001 & 2001 \\
\hline 2016 revenues (rounded) & $\$ 434$ million (+5\%) & $\$ 97$ million (+7\%) & $\$ 187$ million (+5\%) \\
\hline $\begin{array}{l}\text { Number of users at } \\
\text { year-end 2016 (rounded) }\end{array}$ & $850,000(+9 \%)$ & 700,000 & 1.7 million (+10\%) \\
\hline
\end{tabular}

GMPCS = global mobile personal communication by satellite.

Notes: O3b operates in a medium earth orbit. Capital expenditure for these four constellations totals $\$ 7$ billion, ranging from Orbcomm (less than $\$ 300$ million) to Iridium Next (around $\$ 3$ billion).

Source: Adapted from Asia-Pacific Satellite Communications Council. 2018. GEO-HTS and NGSO-HTS. APSCC Quarterly Newsletter. 24(4).

The sheer capacity of bandwidth that low Earth orbit constellations will be able to offer will dwarf existing high-throughput geostationary orbit satellites.

Individual GEO satellites provide bandwidth capacity of 1-10 gigabits per second (Gbps), while the first-generation HTS range is 10-50 Gbps, and third-generation (HTS Class III) provides capacity of 150-350 Gbps (footnote 18). As an example, the Kacific 1 satellite includes 56 individual beams (Kaband), each having a capacity up to $1.25 \mathrm{Gbps}$ (one of the highest signal powers achieved in the region). ${ }^{21}$ With the next generation LEO constellations consisting of hundreds, if not thousands, of satellites each able to transmit tens (10s) of Gbps, the total capacity of new constellations is forecast to be in single digit to 10 s of Tbps, dramatically surpassing existing sellable capacity of GEO (Figure 6). One report forecasts satellite broadband capacity to increase from an estimated 2 Tbps at the end of 2020, to 20 Tbps by end of 2021, and 60 Tbps by the end of the decade. ${ }^{22}$ In Asia, bandwidth demand supplied by non-GEO satellites is forecast to rise dramatically (Figure 7).

Low Earth orbit versus geostationary orbit: differences in subscriber data pricing may be substantial once low Earth orbit commercial services begin.

While prices for wholesale bandwidth are generally not public information, the advent of HTS has led to a divergence in cost for satellite services, with rates for broadband connectivity falling faster than that for broadcast and distribution. ${ }^{23}$ A recent interview by the AID \& International Development Forum with the vice-president for global strategic business development at YahClick (the leading satellite

$21 \quad$ Gunter's Space Page. n.d. JCS at 18/Kacific 1.

22 Based on 20 Tbps from Starlink, up to 5 Tbps from OneWeb, up to 10 Tbps from SES/mPower, and 15 Tbps from Telesat from C. Forrester. 2021. Report: Satellite broadband capacity to grow 10x by year-end. Advanced Television. 12 February.

23 A. Harebottle. 2020. Bandwidth Pricing: How Low Can it Go? Via Satellite. June. 


\section{Figure 5: Comparison of Characteristics: Geostationary Orbit, Medium Earth Orbit, and Low Earth Orbit}

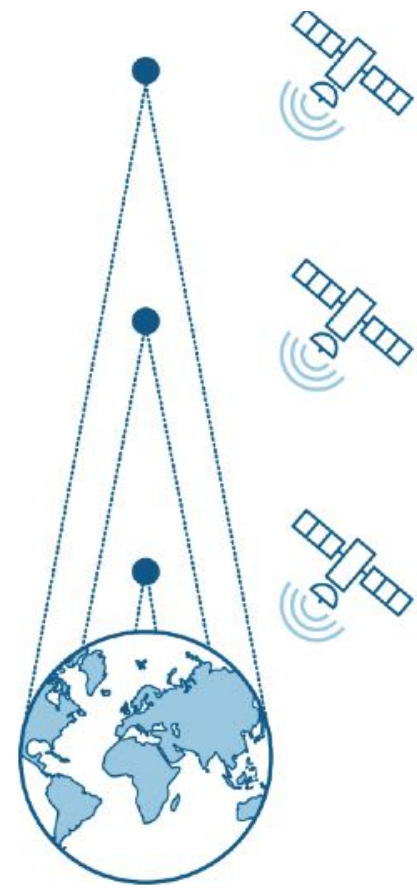

GEO satellites at altitudes of $35,786 \mathrm{~km}$

Full orbital period of 24 hours

Latency (round trip) of approximately $477 \mathrm{~ms}$

MEO satellites at altitudes of 2,000-35,786 km

Full orbital period of 127 minutes to 24 hours

Latency (round trip) of approximately $27-477 \mathrm{~ms}$

LEO satellites at altitudes of 160-2,000 km

Full orbital period of 88-127 min

Latency (round trip) of approximately $2-27 \mathrm{~ms}$

\begin{tabular}{|c|c|c|c|c|c|c|}
\hline Orbit & Altitude & $\begin{array}{l}\text { Orbital } \\
\text { Period }\end{array}$ & $\begin{array}{l}\text { Latency } \\
\text { (round trip) }\end{array}$ & $\begin{array}{l}\text { Number of } \\
\text { Satellites to } \\
\text { Span Globe }\end{array}$ & $\begin{array}{c}\text { Cost per Satellite } \\
(\$)\end{array}$ & $\begin{array}{l}\text { Effective } \\
\text { Lifetime of } \\
\text { Satellite }\end{array}$ \\
\hline GEO & $35,786 \mathrm{~km}$ & 24 hours & $\sim 477 \mathrm{~ms}$ & $3^{a}$ & $\begin{array}{l}\text { Approximately } \\
\text { 100-400 million }\end{array}$ & $15-20$ years \\
\hline MEO & $\begin{array}{c}2,000-35,786 \\
\mathrm{~km}^{\mathrm{b}}\end{array}$ & $\begin{array}{c}127 \text { min-24 } \\
\text { hours }\end{array}$ & $\sim 27-\sim 477 \mathrm{~ms}$ & $\begin{array}{l}5-30 \\
\text { (depending on } \\
\text { altitude) }\end{array}$ & $\begin{array}{l}\text { Approximately } \\
80-100 \text { million }\end{array}$ & $10-15$ years \\
\hline LEO & $160-2,000 \mathrm{~km}$ & $88-127 \mathrm{~min}$ & $\sim 2-27 \mathrm{~ms}$ & $\begin{array}{l}\text { hundreds or } \\
\text { thousands } \\
\text { (depending on } \\
\text { altitude) }\end{array}$ & $\begin{array}{l}\text { Approximately } \\
0.5-45 \text { million }\end{array}$ & $5-10$ years \\
\hline
\end{tabular}

$\mathrm{GEO}=$ geostationary orbit, $\mathrm{km}$ = kilometer, $\mathrm{LEO}=$ low Earth orbit, $\mathrm{MEO}=$ medium Earth orbit, $\min =$ minute, $\mathrm{ms}=$ millisecond.

Note: Not depicted are small satellites, nano satellites, cube satellites in the range of 50-500 kilograms that are typically used for gathering scientific data and radio relay.

a This excludes high-latitude areas, i.e., above the polar circles.

b Theoretically; in practice, 5,000-20,000 km.

Source: International Telecommunication Union. 2020. The Last-Mile Internet Connectivity Solutions Guide: Sustainable Connectivity Options for Unconnected Sites. 
Figure 6: Total Sellable Satellite Bandwidth Capacity, 2019-2025

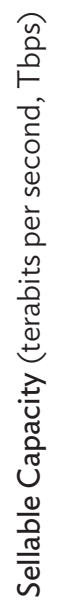

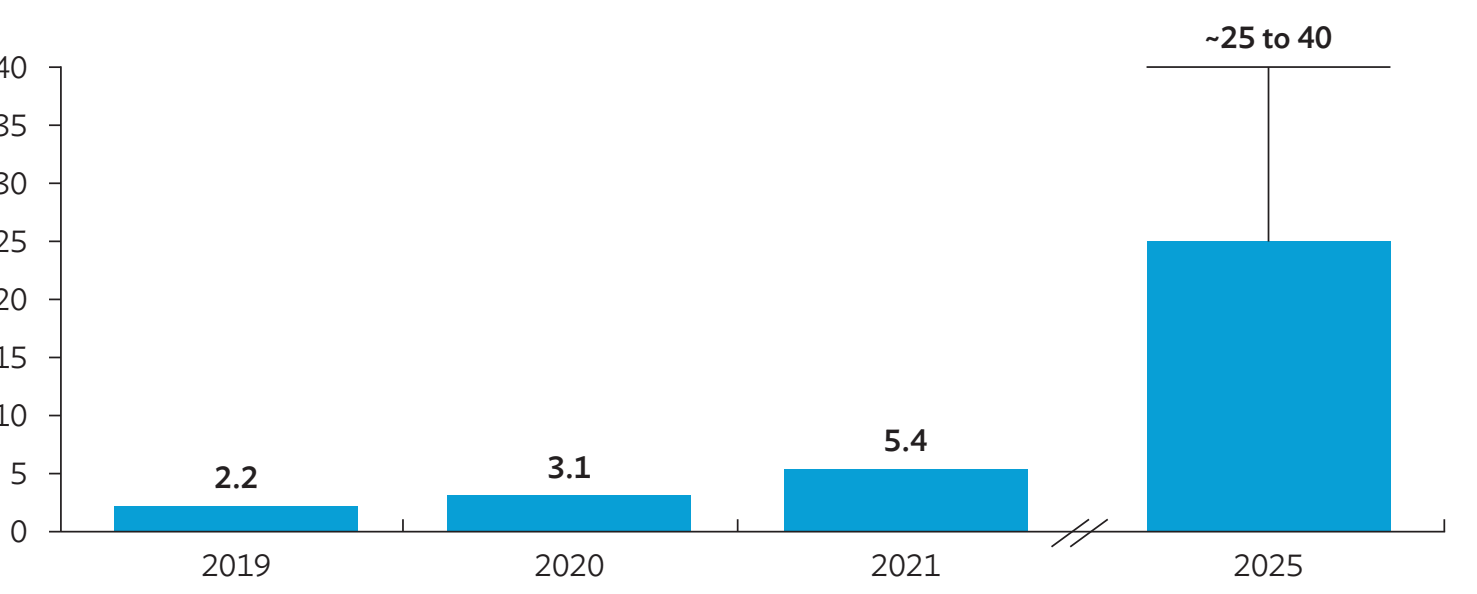

Note: Capacity figures in the table represent theoretical peak (not sellable capacity).

Sources: Adapted from OneWeb. 2019. One Web Overview. A company profile shared during the conduct of research for this paper; Based on calculations from R. Barney. 2018. Telesat Says Ideal LEO Constellation is 292 Satellites, But Could Be 512; C. Henry. 2018a. EchoStar Buys Jupiter-3 “Ultra High Density Satellite” from SSL; C. Henry. 2018b. SES, With FCC's Blessing, Says O3b Constellation Can Reach Global Coverage; Viasat. 2018. Viasat Announces Highest-Speed, Unlimited Satellite Internet Service - Nationwide.

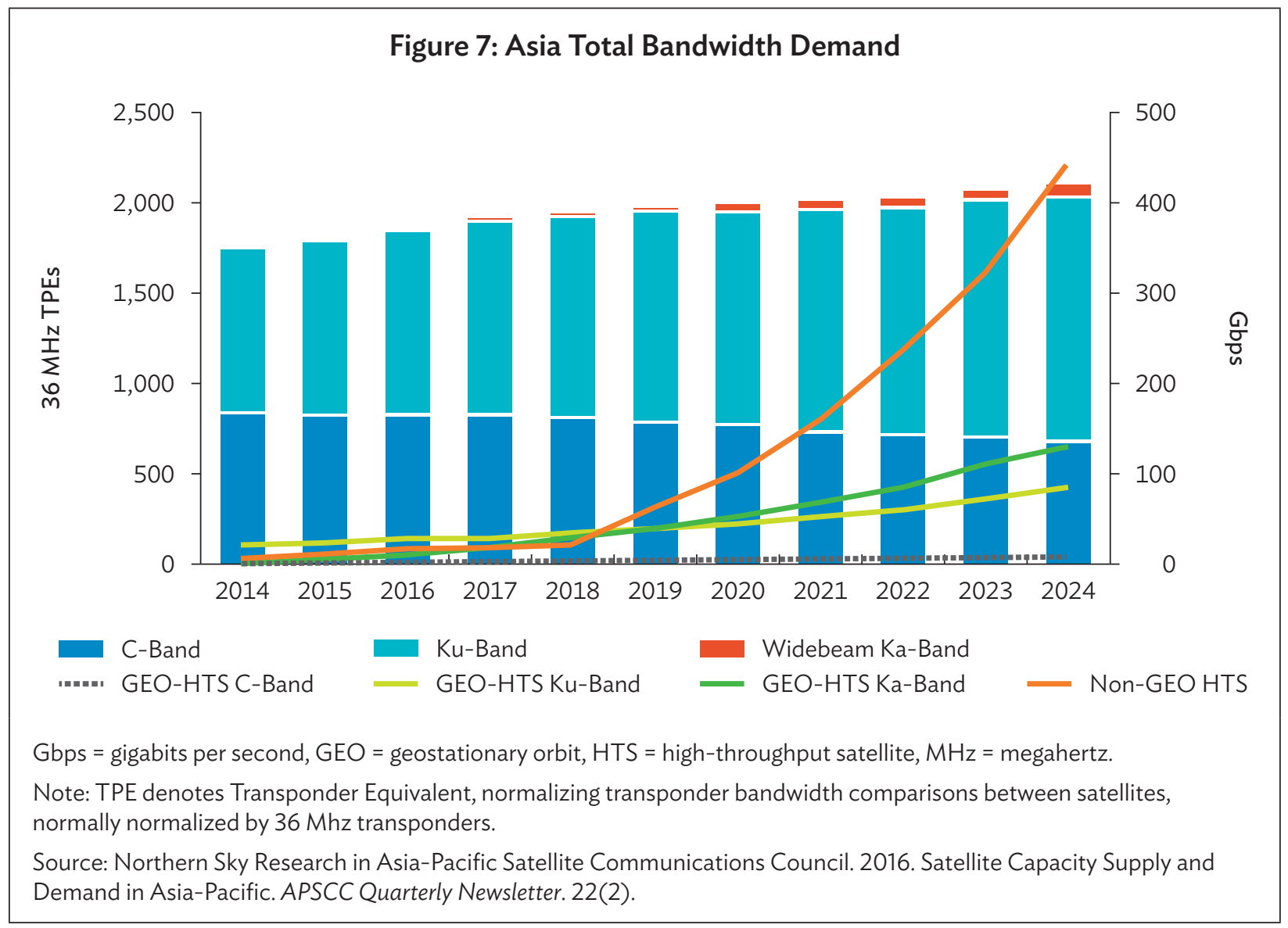


broadband service of United Arab Emirates-based global satellite operator Yahsat and its partner Hughes), noted that for HTS GEO service offerings, the "average bandwidth cost [is] between $\$ 250$ and $\$ 400$ per Mbps per month." 24 Over the coming decade, wholesale rates are expected to fall below $\$ 100$ per Mbps per month, with one notable event in 2019 when it fell below $\$ 50$ per Mbps per month in a unique circumstance (footnote 24).

As LEO and MEO satellites become more ubiquitous, these technologies are expected to provide a cost advantage compared to GEO satellites. Since LEO constellations are expected to provide identical coverage for the service area under the constellation's footprint, they could potentially offer a uniform pricing model anywhere in the world (footnote 24). Combined with the high-capacity, shorter-term (and, therefore, more competitive) contracts, LEOs could rapidly decrease satellite bandwidth costs globally. There will also be significant opportunity for regional pricing due to the fact that the up-front investment in the constellation is the primary cost, and individual satellites are only able to serve the area under their current location.

One of the new LEO constellations in deployment is SpaceX's Starlink service, which is the most advanced LEO constellation in deployment in terms of number of satellites and current stage of internet service offered. Starlink began a public beta trial program in October 2020 for subscribers in the northern United States (US) and Canada between the latitudes of $45^{\circ}$ and $52^{\circ}$ focusing on rural locations (called the "Better Than Nothing Beta"). ${ }^{25}$ The service pricing offered during the public beta is $\$ 99 /$ month for speeds between 50-150 Mbps, latency between 20-40 milliseconds, plus a one-time equipment fee of $\$ 499$. No data cap has yet been implemented. ${ }^{26}$ Based on this data, a per Mbps price comparison would see Starlink at \$0.50-\$1.50/Mbps compared to a range of pricing from HTS GEO services shown in Table 2. It is important to note that this comparison should be revised when commercial pricing of LEO becomes available.

Even as prices have fallen over the years, satellite broadband remains expensive compared to connectivity from terrestrial technologies at the same speeds. This is particularly relevant for Asia and the Pacific, where providers have to contend with users who have less disposable income relative to users elsewhere in the world. ${ }^{27}$ MEASAT's CONNECTme, for example, offers a $25 \mathrm{Mbps}$ download/1 Mbps upload monthly postpaid plan with a 60 GB monthly data cap for nearly $\$ 48$ in Malaysia. ${ }^{28}$ Meanwhile, Maxis, one of the country's fiber broadband providers, offers a $100 \mathrm{Mbps}$ download/50 Mbps upload monthly unlimited data plan at closer to $\$ 31$ a month where its fiber cable network is available. ${ }^{29}$

24 Note: This is average bandwidth cost between $\$ 250-\$ 400$ per Mbps per month [for] Ka-band versus $\$ 800-\$ 1,400$ per Mbps per month for Ku-band. Aid and International Development Forum. 2019. Ka vs. Ku Band: Which is the Best for Satellite Broadband? 24 September.

25 Beta service began in the UK in December 2020; Western Germany and New Zealand in March 2021; and Starlink has initiated global pre-orders around the world with estimated coverage start dates. M. Kan. 2021. SpaceX Opens Starlink Pre-Orders, But It May Take Months to Arrive. PC Mag Asia. 10 February; Pre-orders are being accepted in at least 18 different countries. Comms Update. 2021. Starlink pre-ordering in at least 18 countries; keen interest reported in Canada. 15 February.

26 M. Brown. 2020. SpaceX Starlink Beta Test: Coverage Area, Pricing and More. Inverse. 21 July.

27 A. Harebottle. 2018. Will LEO Kickstart the Asian Broadband Market? Via Satellite.

28 Pricing information from Connect.Me.

29 Pricing information from Maxis. Maxis Fibre Broadband. 
The retail satellite broadband market in parts of Asia and the Pacific is less mature than that of other regions, with retail subscriptions lagging in speed, price, and data allocation. This is illustrated in Table 2, which contains a summary of retail satellite broadband packages offered in various countries. ${ }^{30}$ All of these options use GEO satellites, which have high latency and limited coverage areas.

Table 2: Sample Retail Satellite Service Offerings (Advertised Maximum Speeds, Not Dedicated or Committed Throughput)

\begin{tabular}{|c|c|c|c|c|c|c|c|}
\hline $\begin{array}{l}\text { Satellite } \\
\text { Provider }\end{array}$ & $\begin{array}{l}\text { Country } \\
\text { of Service } \\
\text { Offering }\end{array}$ & $\begin{array}{l}\text { Local Service } \\
\text { Provider }\end{array}$ & $\begin{array}{l}\text { Download } \\
\text { Speed }\end{array}$ & $\begin{array}{l}\text { Upload } \\
\text { Speed }\end{array}$ & Data Cap & $\begin{array}{c}\text { Price } \\
\text { per month } \\
(\$)\end{array}$ & $\begin{array}{c}\text { Price } \\
\text { per Mbps } \\
\text { per month } \\
\text { (download; } \\
\$ \text { ) }\end{array}$ \\
\hline SES & Philippines & $\begin{array}{c}\text { iGSat Satellite } \\
\text { Broadband/ } \\
\text { Delco Telecoms }\end{array}$ & $\begin{array}{l}\text { Up to } \\
5 \mathrm{Mbps}\end{array}$ & $\begin{array}{l}\text { Up to } \\
1 \mathrm{Mbps}\end{array}$ & $40 \mathrm{~GB}$ & 276.65 & 55.33 \\
\hline $\begin{array}{l}\text { Thaicom/ } \\
\text { IPStar }\end{array}$ & Philippines & $\begin{array}{l}\text { We are IT } \\
\text { Phils. Inc. }\end{array}$ & $\begin{array}{l}\text { Up to } \\
4 \mathrm{Mbps}\end{array}$ & $\begin{array}{l}\text { Up to } \\
1 \mathrm{Mbps}\end{array}$ & Unlimited & 79.27 & 19.82 \\
\hline $\begin{array}{l}\text { Hughes } \\
\text { (JUPITER) }\end{array}$ & Indonesia & $\begin{array}{l}\text { Telkomsat/ } \\
\text { Mangoesky }\end{array}$ & $\begin{array}{l}\text { Up to } \\
6 \mathrm{Mbps}\end{array}$ & $\mathrm{n} / \mathrm{a}$ & $10 \mathrm{~GB}$ & 52.02 & 8.67 \\
\hline Hughes & $\begin{array}{l}\text { United } \\
\text { States }\end{array}$ & HughesNet & $\begin{array}{c}\text { Up to } \\
25 \mathrm{Mbps}\end{array}$ & $\begin{array}{l}\text { Up to } \\
3 \mathrm{Mbps}\end{array}$ & $50 \mathrm{~GB}$ & 149.99 & 6.00 \\
\hline ViaSat & $\begin{array}{l}\text { United } \\
\text { States }\end{array}$ & Viasat/Exede & $\begin{array}{c}\text { Up to } \\
25 \mathrm{Mbps}\end{array}$ & $\begin{array}{l}\text { Up to } \\
3 \mathrm{Mbps}\end{array}$ & 60 GB soft cap & 100 & 4.00 \\
\hline MEASAT & Malaysia & CONNECTme & $\begin{array}{c}\text { Up to } \\
25 \mathrm{Mbps}\end{array}$ & $\begin{array}{l}\text { Up to } \\
1 \mathrm{Mbps}\end{array}$ & $60 \mathrm{~GB}$ & 47.83 & 1.91 \\
\hline Sky Muster & Australia & ipstar/nbn & $\begin{array}{c}\text { Up to } \\
25 \mathrm{Mbps}\end{array}$ & $\begin{array}{l}\text { Up to } \\
5 \mathrm{Mbps}\end{array}$ & $\begin{array}{l}50 \text { GB peak + } \\
50 \text { GB offpeak }\end{array}$ & 47.47 & 1.90 \\
\hline Eutelsat & France & Orange/Nordnet & $\begin{array}{c}\text { Up to } \\
100 \mathrm{Mbps}\end{array}$ & $\begin{array}{l}\text { Up to } \\
5 \mathrm{Mbps}\end{array}$ & $\begin{array}{c}150 \mathrm{~GB} \\
\text { prioritized/soft cap }\end{array}$ & 79.85 & 0.80 \\
\hline
\end{tabular}

$\mathrm{GB}=$ gigabyte, $\mathrm{Kbps}=$ kilobits per second, $\mathrm{Mbps}=$ megabits per second.

Sources: Author's analysis and survey; service packages, and foreign exchange rate as of 3 April 2021.

30 Data compiled from service providers' marketing materials. 


\section{Comparing low Earth orbit constellations shows that Starlink is ahead of its competitors in terms of deployment and service position.}

Four main companies take the spotlight in terms of next-generation LEO constellation deployment for broadband communications (though the European Union, the People's Republic of China, and the Russian Federation all recently announced LEO constellations). ${ }^{31}$ These four are Starlink by SpaceX, OneWeb, Lightspeed by Telesat, and Project Kuiper by Amazon.

Starlink is by far the most advanced in its satellite deployments with 1,445 satellites launched (as of 7 April 2021) at approximately $550 \mathrm{~km}$ above Earth. Announced in 2015 by SpaceX, its constellation is meant to initially deploy approximately 1,440 of the 260-kilogram (or 570-pound) satellites to begin providing near-global low-cost internet connectivity service with speeds that rival that of fiber-optic cable technology by 2021. The estimated cost of decade-long project (design, build, deploy) approximately $\$ 10$ billion. ${ }^{32}$ On 15 October 2019, the FCC submitted filings to the ITU on SpaceX's behalf to arrange spectrum for 30,000 additional Starlink satellites to supplement the 12,000 Starlink satellites already approved by the FCC. ${ }^{33}$ SpaceX's obvious advantage is its industry-leading launch capability with reusable rockets enabling them to launch satellites at a fraction of the cost of other launch providers.

In comparison, OneWeb has the second most number of satellites launched with 146 satellites in orbit (as of 7 April 2021). ${ }^{34}$ The company was founded in 2012, raised over $\$ 3$ billion from various investors (including Softbank), but went into bankruptcy in March 2020 citing difficulties in raising capital. ${ }^{35}$ However, OneWeb came out of bankruptcy proceedings with the Government of the United Kingdom acquiring a 45\% stake for $\$ 500$ million in July 2020 and India's Bharti Global also committing investment. ${ }^{36}$ In January 2021, OneWeb announced an additional capital infusion of $\$ 400$ million from SoftBank and Hughes Network Systems, for a total of $\$ 1.4$ billion since restructuring which OneWeb says will fund the deployment of 648 satellites planned for launch by the end of 2022 to provide global coverage. ${ }^{37}$ Bharti Founder and OneWeb Executive Chair Sunil Bharti Mittal indicates that $\$ 2.3$ billion to $\$ 2.4$ billion is required to complete the first phase. ${ }^{38}$

31 S. Chaudhary. 2020. China Plans to Launch 10,000 Satellites to Compete With Elon Musk's SpaceX. The EurAsian Times. 19 November; TASS Russian News Agency. 2018. Russia to create orbital Internet satellite cluster by 2025. 22 May; J. O'Callaghan. 2020. Europe Wants to Build Its Own Satellite Mega Constellation to Rival SpaceX's Starlink. Forbes. 23 December.

Other planned LEO constellations for communications (though narrowband) include Lynk, which is aiming to launch 1,000 satellites positioned at $450 \mathrm{~km}$ to $500 \mathrm{~km}$ to provide voice and messaging services: J. Foust. 2021. Lynk to soon begin tests of cellular connectivity using first satellite.

32 G. Shotwell. 2018. SpaceX's Plan to Fly You Across the Globe in 30 Minutes. Speech delivered for TedTalks on 14 May 2018. SpaceX. Starlink Mission. Youtube.

33 C. Henry. 2019. SpaceX Submits Paperwork for 30,000 More Starlink Satellites. Space News. 15 October.

34 S. Mathewson. 2021. Arianespace to Launch New Fleet of OneWeb Internet Satellites Tonight. Here's How to Watch. Space.com. 24 March; and Facebook.com. OneWeb Launch \#5.

35 M. Holmes. 2020. In the Eye of the Storm: Greg Wyler Breaks Cover to Talk OneWeb. Via Satellite; and J. Wattles. 2020. Softbank-Backed Satellite Startup OneWeb Files for Bankruptcy. CNN Business. 28 March.

36 Government of the United Kingdom. 2020. UK Government to Acquire Cutting-Edge Satellite Network. 3 July; C. Gebhardt. 2020. UK Government Acquires OneWeb in Curious Move. NASA Space Flight. 3 July; and L. Goulding. 2020. Untangling the OneWeb Web. London Economics: Space in Focus. Issue No. 3. 27 August.

37 L. Hardesty. 2021. OneWeb Raises \$400M from SoftBank, Hughes. Fierce Wireless. 15 January; and I. Lunden. 2021. OneWeb has Now Raised \$1.4B, with \$400M from SoftBank and Hughes, to Help Fund its First Satellite Fleet. Tech Crunch. 15 January.

$38 \quad$ BBC. "Satellites to breach the digital divide." (Minute 11:34). 
Canadian Telesat began in 1969 with decades of experience in satellite communications. Its LEO plans began in 2016 with an announcement to launch 120 satellites. In 2018, its first (and only) LEO satellite in orbit was launched as it began testing and in 2021, it announced details of its LEO constellation, named Lightspeed, consisting of 298 satellites. ${ }^{39}$ Telesat is expected to start launching satellites in 2023 (on Amazon's Blue Origin launch vehicles) and the constellation is expected to cost $\$ 5$ billion. ${ }^{40}$

The newcomer of the group is Amazon with its Project Kuiper announced in 2019. In July 2020, it announced planned investment of more than $\$ 10$ billion, supported in part by its Blue Origin company, focused on reusable launch rockets. ${ }^{41}$ Project Kuiper has not yet launched any satellites, but has Federal Communications Commission (FCC) approval for 3,236 satellites with commercial service beginning once 578 satellites are in orbit. ${ }^{42}$ Project Kuiper is expected to launch half of its satellites by 2026 and the remainder by 2029 (footnote 41). Table 3 shows a comparison of the different companies' deployments, constellations, and satellites. Other LEO satellite constellations have been announced, but have not reached similar levels of (planned) deployment and/or information about their plans is not publicly available.

\section{Significant differences planned in constellation configurations.}

The three constellations with current deployments (Starlink, OneWeb, and Telesat) have significant differences in configuration and satellites. Starlink satellites are configured to have lower orbit altitude than its competitors, its latest configuration at up to $550 \mathrm{~km}$ off the ground. ${ }^{43}$ This will provide lower latencies for satellite-to-earth and earth-to-satellite communication. It originally planned to include optical inter-satellite links (OISL) which would reduce latency even further over long distances and provide communications that could theoretically even be faster than fiber optic cable (due to the vacuum in space). However, inter-satellite links have not yet been fully deployed, and only a few of the satellites launched to date include OISL technology. ${ }^{44}$

In Telesat's constellation, each satellite will be an internet protocol node, with each satellite functioning as a router making decisions on where to send traffic. Telesat's more complex design helps to optimize network architecture and efficiency as its satellites orbit at a higher altitude and will be equipped with OISL.

39 Telesat. 2021. Telesat to Redefine Global Broadband Connectivity with Telesat Lightspeed, the World's Most Advanced Low Earth Orbit (LEO) Satellite Network. 9 February.

40 M. Sheetz. 2021. Telesat to build $\$ 5$ billion global satellite network to bring fiber-linked internet to businesses; Forrester. 2020. Telesat to Start LEO Services in 2022. Advanced Television. 12 October; Telesat. 2021. Telesat to Redefine Global Broadband Connectivity with Telesat Lightspeed, the World's Most Advanced Low Earth Orbit (LEO) Satellite Network.

41 Tech Portal. 2020. Amazon to Invest \$10Bn on Its SpaceX Starlink Competitor, 'Project Kuiper.' 31 July.

42 E. Blumenthal. 2020. Amazon's Project Kuper Gets FCC approval for Over 3,200 Internet Satellites. CNet. 31 July; Federal Communications Commission. 2020. Order and Authorization.

43 To see Starlink's satellites current position in real time, go to: https://satellitemap.space/.

44 The 24 January SpaceX "Transporter-1" rideshare mission included 10 Starlink satellites, with OISL capability and the first Starlink satellites headed for a polar orbit. S. Clark. 2021. SpaceX Smashes Record with Launch of 143 Small Satellites. Spaceflight Now. 24 January. 
Table 3: Differences in Deployments, Constellations, and Satellites

\begin{tabular}{|c|c|c|c|c|}
\hline Characteristics & $\begin{array}{l}\text { SpaceX } \\
\text { Starlink }\end{array}$ & OneWeb & $\begin{array}{c}\text { Telesat } \\
\text { Lightspeed }\end{array}$ & $\begin{array}{l}\text { Amazon Project } \\
\text { Kuiper }\end{array}$ \\
\hline $\begin{array}{l}\text { Number of LEO satellites } \\
\text { launched }^{a}\end{array}$ & 1,445 & 146 & 1 (Telesat LEO 1) & 0 \\
\hline $\begin{array}{l}\text { Constellation size to initiate } \\
\text { commercial service }\end{array}$ & 1,440 & 648 & 298 & 578 \\
\hline $\begin{array}{l}\text { Estimated total bandwidth } \\
\text { throughput at the start of } \\
\text { commercial operations }\end{array}$ & 23.7 Tbps & 1.56 Tbps & 15 Tbps & unknown \\
\hline $\begin{array}{l}\text { Planned expansion } \\
\text { (total future constellation size) }\end{array}$ & $\begin{array}{c}12,000 \\
\text { (FCC approved) } \\
\text { to } 30,000 \\
\text { (submitted to } \\
\text { FCC) }\end{array}$ & 2,000 & 1,600 & 3,236 \\
\hline Frequency & Ku-band & Ku-band & Ka-band & Ka-band \\
\hline Orbit & $560 \mathrm{~km}$ & $1,200 \mathrm{~km}$ & $1,000 \mathrm{~km}$ & $590-630 \mathrm{~km}$ \\
\hline Satellite mass & $227-260 \mathrm{~kg}$ & $150 \mathrm{~kg}$ & $800 \mathrm{~kg}$ & unknown \\
\hline Satellite life & $5-7$ years & $\sim 5$ years & $10-12$ years & unknown \\
\hline Latency & $<50 \mathrm{~ms}$ & $<50 \mathrm{~ms}$ & $<50 \mathrm{~ms}$ & unknown \\
\hline $\begin{array}{l}\text { Required reported } \\
\text { capital expenditure }\end{array}$ & $\$ 10$ billion & $\$ 2.4$ billion & $\$ 5$ billion & $\$ 10$ billion \\
\hline $\begin{array}{l}\text { Vertical markets } \\
\text { publicly targeted }\end{array}$ & $\begin{array}{c}\text { Consumer } \\
\text { broadband, } \\
\text { cellular backhaul }\end{array}$ & $\begin{array}{l}\text { Backhaul, } \\
\text { government, } \\
\text { mobility, } \\
\text { broadband }\end{array}$ & $\begin{array}{l}\text { Government } \\
\text { mobility, } \\
\text { carrier-grade } \\
\text { requirements }\end{array}$ & $\begin{array}{l}\text { Broadband, } \\
\text { backhaul }\end{array}$ \\
\hline
\end{tabular}

FCC = Federal Communications Commission, $\mathrm{kg}=$ kilogram, $\mathrm{km}=$ kilometer, $\mathrm{LEO}=$ lower Earth orbit, $\mathrm{ms}=$ millisecond, Tbps $=$ terabits per second.

a Two of Starlink's 1,445 satellites launched included in the table are the first two demo satellites, Tintin A and B, and are excluded in some aggregate counts.

Sources: Amazon. 2020. Amazon Receives FCC Approval for Project Kuiper Satellite Constellation. 30 July; Asia-Pacific Satellite Communications Council. 2018. GEO-HTS \& NGSO-HTS. APSCC Quarterly Newsletter. 24(4); A. Burkitt-Gray. 2020. OneWeb Blasts Back Into Action from Russia’s Far East. Capacity Media. 18 December; I. del Portillo et al. 2018. A Technical Comparison of Three Low Earth Orbit Satellite Constellation Systems to Provide Global Broadband. MIT presentation delivered at the 69th International Astronautical Congress. Bremen. 1 October; Euroconsult. 2018. Satellite Communications and Broadcasting Market Survey; Federal Communications Commission. 2020. Order and Authorization; E. Howell. 2020. The FCC Has Approved Amazon's Plan for its Kuiper Satellite Constellation. Here's What that Means. Space.com. 20 August; S. Mathewson. 2021. Arianespace to Launch New Fleet of OneWeb Internet Satellites Tonight. Here's How to Watch. Space.com. 24 March; N. Louise. 2019. Amazon Seeks Permission from FCC to Launch over 3,000 Broadband Internet Satellites for its 'Project Kuiper' Initiative. Tech Startups. 9 July. Telesat. 2021. Telesat to Redefine Global Broadband Connectivity with Telesat Lightspeed, the World's Most Advanced Low Earth Orbit (LEO) Satellite Network. Press release. 6 February. 
Unlike Telesat's model, OneWeb will employ a traditional "bent-pipe" architecture. Signals coming up from the ground will be "repeated" to another beam going down, with no routing taking place, simplifying the networking component of satellite design and engineering, but without the potential benefit of overall network redundancies and efficiency in data packet routing. The differences in orbits and coverage are demonstrated in Figure 8, including differences in average and maximum data rates per satellite.

OneWeb
Figure 8: Differences in Per-Satellite Data Rates

Significant capacity differences between low Earth orbit constellations are driven by constellation size and ground segment components.

Estimates by the Massachusetts Institute of Technology (MIT) in 2018 on total capacity of three of the LEO constellations in current deployment suggested that while each of the constellations will have significant capacity (each over 1 Tbps), Starlink would have the largest throughput at 23.7 Tbps based on 123 ground stations and a total of 4,425 satellites, compared to Telesat with 2.66 Tbps with 40 ground stations and 117 satellites, and OneWeb with 1.56 Tbps based on 71 ground stations and 720 satellites. ${ }^{45}$

45 I. del Portillo et al. 2018. A Technical Comparison of Three Low Earth Orbit Satellite Constellation Systems to Provide Global Broadband. MIT presentation delivered at the 69th International Astronautical Congress. Bremen. 1 October. 
It is important to note these were estimates from over 2 years ago and what this research found was that the capacity and coverage of each constellation is highly dependent on assumptions of satellite fleet size, satellite efficiency, and the number of ground stations demonstrating that Starlink, in particular, would require significant resources for its ground infrastructure with hundreds of ground stations and thousands of gateway antennas. More recent updates from the LEO providers note that commercial service will begin for Starlink with 1,440 satellites, OneWeb with 648 satellites, and Telesat with 298 satellites. $^{46}$

\section{Low Earth orbit user terminal pricing will be an area of intense competition on price and innovation.}

Very small aperture terminals (VSATs) for HTS GEO service range around $\$ 1,000$ each. ${ }^{47}$ The current $\$ 499$ price for the Starlink terminal (named "Dishy McFlatface") is a significant price reduction. However, it is not clear if this price level will be sustained during commercial service and even if so, the up-front cost may price some subscribers out of the market, unless some form of amortized financing is offered.

The level of subsidy that SpaceX may be absorbing per unit is not known, but industry reports suggest that phased array flat panel antennas cost above $\$ 1,000$ per unit. ${ }^{48}$ OneWeb's most affordable user terminal offering is priced at $\$ 1,200$ per unit before freight, taxes, and other costs. However, Starlink should be able to achieve economies of scale with millions of terminals eventually required for its global customer base. ${ }^{49}$ Even Amazon has been detailing its innovations in phased array antenna development, noting successes in designing and developing a small 12-inch antenna. ${ }^{50}$

\section{In-house satellite launch capacity and expertise may result in a competitive advantage for Starlink and, in the future, Project Kuiper.}

Because Starlink benefits from the in-house launch capacity of SpaceX, its launch cost equates to the marginal launch cost (removing profit margin) of Space $X$, which currently gives them a significant cost and capacity advantage over other competitors. The Space X website lists the standard payment plan for a Falcon 9 launch at $\$ 62$ million..$^{51}$ This price level has been steady since 2016, before the current development of reusable stage 1 rockets. At this pricing, it was already winning contracts over other launch vehicles. ${ }^{52}$

46 See Table 3. Including Telesat, 2021; I. Lunden. 2021. OneWeb has Now Raised \$1.4B, with \$400M from SoftBank and Hughes, to Help Fund its First Satellite Fleet. Tech Crunch. 15 January.

47 Based on: (i) author's project deployment experience, including as chief technical advisor on a 5,000-site VSAT deployment; (ii) conversations with Ka-band satellite provider; and (iii) product lists, such as at https://www.vsatsystems.com/End-User-Service/Equipment-Pricing/.

48 P. de Selding. 2020. Modem Antenna Designer Satixfy's CEO: OneWeb and SpaceX Starlink are Dreaming. Space Intel Report. 7 October; and D. Mohney. 2020. SpaceX Has a Lot Riding on Starlink’s \$499 “UFO on a Stick." Space News. 19 November.

49 Once at scale deployment, consumer financing may also come into play such that installations will be $\$ 0$ up-front for qualifying individuals.

50 Amazon. 2020. Nima Mahanfar Discusses the Science Behind Project Kuiper Customer Terminal Antenna. Amazon Science. 16 December.

51 SpaceX. n.d. Capabilities and Services.

52 M. Brown. 2020. SpaceX: Elon Musk Breaks Down the Cost of Reusable Rockets. Inverse. 22 September; M. Baylor. 2018. With Block 5, SpaceX to Increase Launch Cadence and Lower Prices. NASA Space Flight. 17 May. 
With the development of reusable rockets, starting with the first stage component of Falcon 9, the standard price for a Falcon 9 launch appears to have dropped to $\$ 50$ million. ${ }^{53}$ Estimates suggest this could drop further to $\$ 36$ million with reusability across all launch costs, ${ }^{54}$ and even SpaceX chief executive officer Elon Musk has suggested that with further optimization of launch operations and full reusability, the marginal cost could drop to $\$ 5$ million- $\$ 6$ million for a Falcon 9 launch. ${ }^{55}$ This suggests, even at the $\$ 36$ million price level, the launch price per payload is already one of the cheapest on the planet (footnote 52). Falcon Heavy's payload is roughly 3 times larger at 1.5 times the price and the company is currently developing an even larger rocket system, the Interplanetary Transport System, renamed StarShip, which is designed to dramatically increase space payload capacity up to 150,000 kilograms, or up to 400 Starlink satellites, per launch (Figures 9 and 10).

\section{In-house satellite production could also factor as a cost and management advantage for Starlink compared to other low Earth orbit constellations that outsource satellite manufacturing.}

SpaceX itself manufactures Starlink satellites whereas other LEO providers rely on sourcing satellites from external parties, particularly from Boeing and Airbus. Telesat, for example, is working with Airbus, Thales Alenia Space, and Maxar for its satellites, while OneWeb has partnered with Airbus. ${ }^{56}$ Amazon has announced that it will be building its own satellites at its facilities in Washington state in the US.

The vertical integration in both Amazon's and Starlink's production and launch will give them deployment advantages and cost efficiencies. While satellite production costs are proprietary information, disclosures by SpaceX suggest each satellite's capital expenditure cost is below $\$ 500,000 .{ }^{57} \mathrm{It}$ is worth noting that each Starlink satellite can transmit roughly $20 \mathrm{Gbps}$ of capacity per satellite, while an HTS GEO has a capital expenditure range between $\$ 200$ million for $10 \mathrm{Gbps}$ on the low end, to $\$ 700$ million for 1,000 Gbps on the high end, including launch costs. ${ }^{58}$ This makes LEO significantly cheaper on a per Gbps basis, but each geographic service area requires many LEOs in orbit versus only one GEO. One should note that LEO satellites are designed for shorter life spans (see Table 3 showing LEO life spans ranging from 5-12 years) compared to GEO satellites with a minimum 15 years of useful life.

53 R. Smith. 2020. How Much Cheaper are SpaceX Reusable Rockets? Now We Know. MSN Money. 10 May; and M. Baylor. 2018. With Block 5, SpaceX to Increase Launch Cadence and Lower Prices. NASA Space Flight. 17 May.

54 R. Smith. 2020. How Much Cheaper are SpaceX Reusable Rockets? Now We Know. MSN Money. 10 May.

55 M. Baylor. 2018. With Block 5, SpaceX to Increase Launch Cadence and Lower Prices. NASA Space Flight. 17 May.

56 Telesat. 2018. Telesat Signs Airbus Defence and Space to Further Develop the Design for Telesat's Global LEO Satellite Constellation. 1 August; Telesat. 2021. Telesat to Redefine Global Broadband Connectivity with Telesat Lightspeed, the World's Most Advanced Low Earth Orbit (LEO) Satellite Network; OneWeb; Airbus. 2021. OneWeb Satellites Constellation: Connection for People All over the Globe. Note that Kacific, which launched a Ka-band GEO HTS covering Southeast Asia and the Pacific in December 2019, contracted Boeing for its satellite manufacture and SpaceX for the launch vehicle: C. Henry. 2019. Kacific, with SpaceX Launch Imminent, Borrows $\$ 160$ Million for Satellite Refinancing. Space News. 6 December.

57 E. Ralph. 2019. SpaceX Announces Second Starlink Satellite Launch in Two Weeks. Teslarati.com. 10 December.

58 Asia-Pacific Satellite Communications Council, 2018. 


\section{Figure 9: SpaceX Launch Pricing}

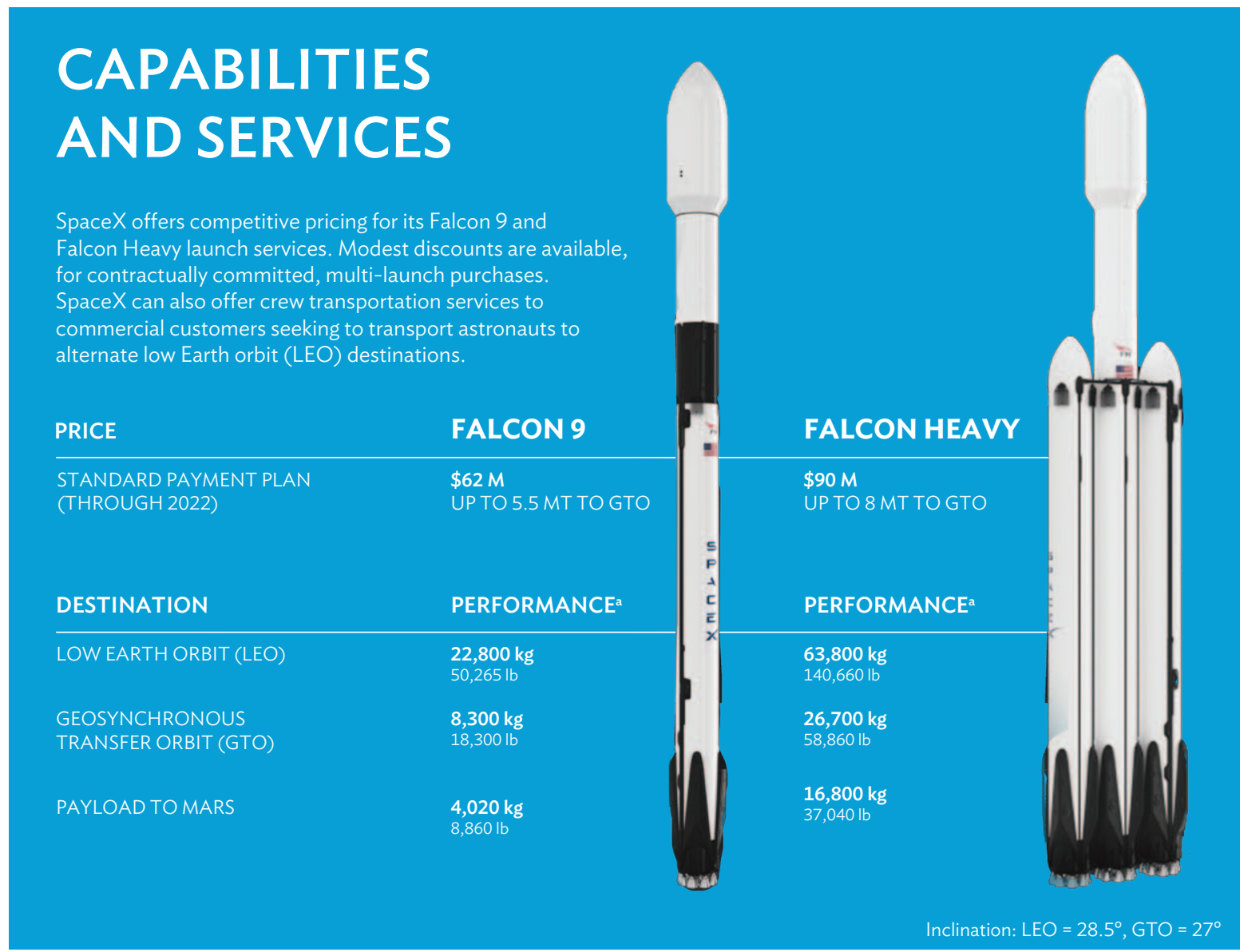

$\mathrm{kg}=$ kilogram, $\mathrm{lb}=$ pound, $M=$ million, $M T$ = metric ton.

a Performance represents maximum capability on fully expendable vehicle.

Source: SpaceX. n.d. Capabilities and Services.

\section{Differences in target markets: consumer, enterprise, government, and telecommunications} (backhaul).

Differences in target markets and customer base are difficult to determine prior to the launch of commercial services. However, Telesat, for example, has publicly expressed a focus on government clients and large enterprises requiring global connectivity. OneWeb, prior to restructuring, focused on connecting the last mile and unconnected communities in emerging markets as well as mobile cellular backhaul. Starlink has focused on unserved consumers with income levels that can afford its service offerings, as well as noting a potential strategy to deploy community wireless fidelity (Wi-Fi) models. Of note is that Starlink has partnered with Microsoft to connect its network directly to the latter's Azure cloud and data center infrastructure, suggesting a focus on enterprise and government clients. Similarly, Amazon's Project Kuiper will no doubt leverage the Amazon Web Services cloud as part of its service offering. 
Figure 10: SpaceX StarShip Compared to Renders of Falcon 9 and Dragon Payloads
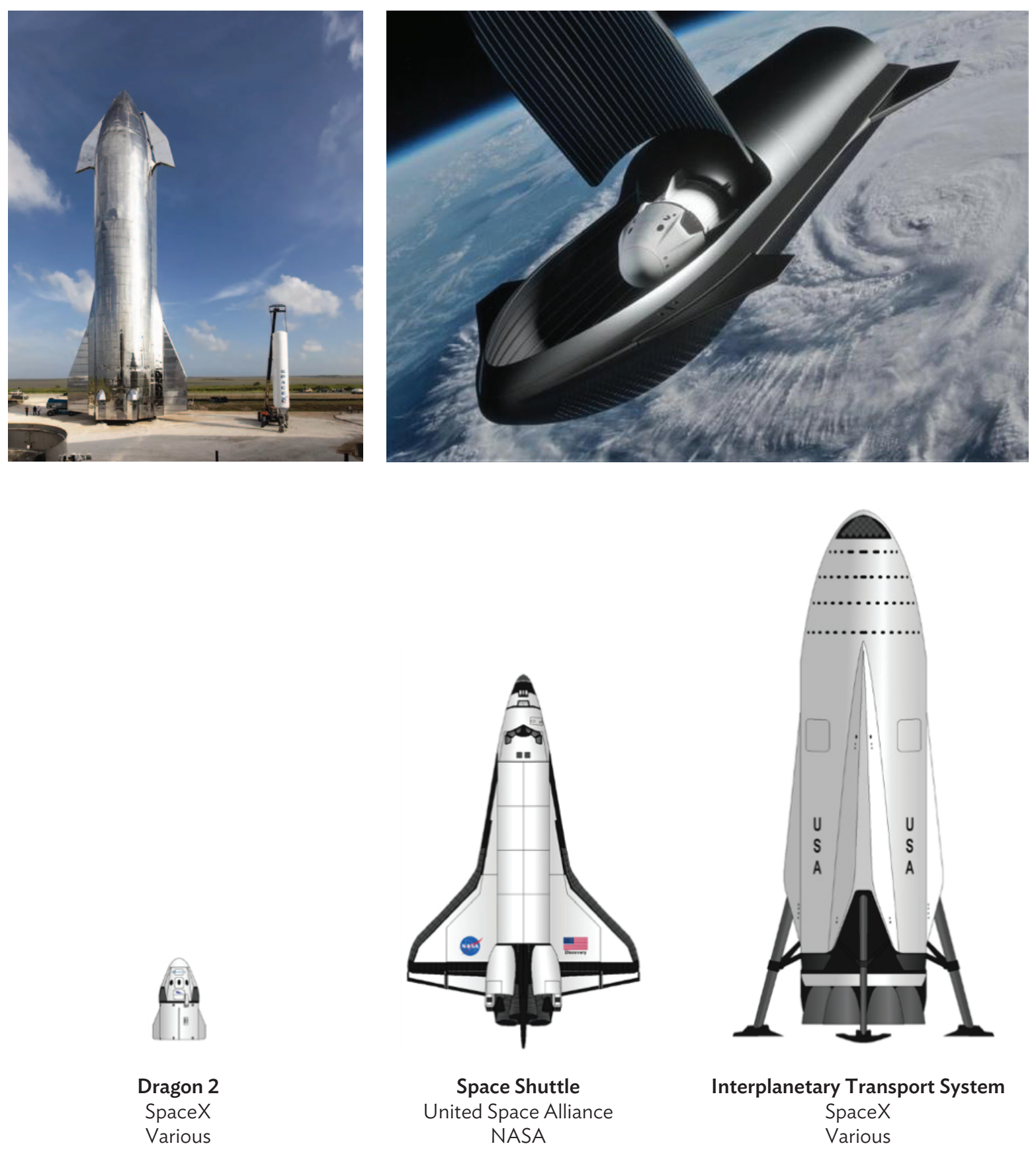

NASA = National Aeronautics and Space Administration

Sources: J. Wendel. 2020. SpaceX CEO Elon Musk Explains Why We Need a 'Whole New Architecture' for Space Travel. Space.com. 10 March; Reddit.com. 2020. Starship vs. Crew Dragon; and Reddit.com. 2020. 21st Century Vehicles of Human Spaceflight. 


\section{IN FOCUS: STARLINK'S DEPLOYMENT, DIFFERENTIATION, AND VIABILITY}

\section{Starlink's 1,445 satellites launched is by far the most advanced stage of deployment by any lower Earth orbit constellation.}

SpaceX is an American aerospace manufacturer and space transportation services company founded in 2002 by Elon Musk, a South African-born American entrepreneur. Musk is a serial entrepreneur starting and selling several companies, including PayPal. Musk also started Tesla Motors in 2003. SpaceX is headquartered in Hawthorne, California and has achieved a number of milestones in space flight, including the first private company to launch a liquid-propellant rocket to reach orbit (Falcon 1 in 2008); successfully launch, orbit, and recover a spacecraft (Dragon in 2010); send a spacecraft to the ISS (Dragon in 2012); launch an object into orbit around the Sun (Falcon Heavy's payload of a Tesla Roadster in 2018); and send astronauts into orbit and to the ISS (SpaceX Crew Dragon Demo-2 and SpaceX Crew-1 missions in 2020).

SpaceX was the first to demonstrate vertical takeoff and vertical propulsive landing for an orbital rocket (Falcon 9 in 2015) and first reuse of an orbital rocket (Falcon 9 in 2017). SpaceX has flown 20 cargo resupply missions to the ISS under a partnership with the National Aeronautics and Space Administration (NASA), as well as an uncrewed demonstration flight of Dragon 2 spacecraft (Crew Demo-1) on 2 March 2019, and the first crewed Dragon 2 flight on 30 May 2020. As of early 2021, SpaceX has contracts in the billions of dollars for space launch of satellites and missions of NASA.

\section{Coverage across Asia and the Pacific may not occur until mid- to late-2021 and into 2022.}

While Starlink's current public beta trial is serving customers in northern US and Canada between latitudes of $45^{\circ}$ and $52^{\circ}$, the expectation is that service will expand to the $33^{\circ}$ latitude by the beginning of 2021, and then to full equatorial coverage the middle to end of 2021. Commercial operations have already begun in Australia and New Zealand, focused on establishing earth stations. ${ }^{59}$ Note that commercial operations may begin once 1,440 satellites are in orbit, but publicly available calculations of broadband throughput are based on a constellation estimate of 4,425 satellites, making the time frame for coverage and throughput across Asia and the Pacific uncertain.

\section{Financial Viability}

Starlink's current public beta pricing structure ( $\$ 99$ per month) suggests strong revenue potential from a discrete base of subscribers. Even before the start of commercial service, Starlink was awarded an $\$ 885$ million contract by the FCC in December 2020, to provide broadband internet service to 642,000 locations. ${ }^{60}$ Morgan Stanley analysis forecasts Starlink revenue in the $\$ 20$ billion to $\$ 30$ billion range within

59 H. Burrell. 2021. What's Elon Musk's Starlink Doing in New Zealand. The Business Desk. 2 January.

60 D. Shepardson. 2020. FCC Awards \$9.2 Billion to Deploy Broadband to 5.2 Million U.S. Homes, Businesses. Reuters.com. 8 December. 
7-10 years of initiating commercial revenues. ${ }^{61}$ At the current beta pricing level, such revenue projections would require roughly 25 million subscribers across the world where Starlink has service footprint. In comparison, US fiber cable provider Comcast alone had 26.9 million residential high-speed internet subscribers in the first quarter of $2020 .{ }^{62}$ As such, Starlink's revenue is forecast to dwarf SpaceX's launch revenue by the mid-2020s. ${ }^{63}$ The combined revenue streams (satellite broadband and space launch) are expected to grow SpaceX into a $\$ 100$ billion+ company in terms of valuation. ${ }^{64}$

\section{OPPORTUNITIES AND BARRIERS TO LEVERAGING LOW EARTH ORBIT SATELLITES IN DEVELOPING MEMBER COUNTRIES}

\section{Satellite connectivity demand in Asia and the Pacific is forecast to grow rapidly.}

Satellite broadband is a growing, and dominant, segment of the overall satellite sector. Overall, the sector's revenues have been growing almost $4 \%$ per year and have increased by $\$ 38$ billion over the last 5 years. The space market is expected to reach between $\$ 1.1$ trillion to $\$ 2.7$ trillion in the next 30 years, with the provision of internet access via satellite predicted to account for $50 \%-70 \%$ as the primary driver of growth. ${ }^{65}$ Figure 11 highlights the growth of GEO HTS bandwidth demand driven by broadband access and enterprise data traffic. Figure 12 forecasts that LEO and MEO satellites will capture half of the market for high-throughput satellite communications by 2027.

\section{Low-cost, high-capacity coverage over an entire country gives governments an alternative to} national satellite launches.

A number of governments in Asia are directly investing in launching their own national satellites (Table 4) with capital expenditures (CAPEX) and launch costs in the hundreds of millions of dollars. Starlink and other LEO constellations could serve as an alternative in supporting universal access objectives of national satellites. Figure 13 compares generations of GEO satellites, including HTS. While a direct comparison to LEO is challenging due to the differences in constellation design, assuming Starlink's total constellation capacity of 20 Tbps and $\$ 10$ billion in forecast CAPEX investment, the equivalent CAPEX per Gbps ratio would be $\$ 0.5$ (for comparison purposes only).

$61 \quad$ A. Jonas et al. 2019. SpaceX, Starlink, and Tesla: Moving into Orbit? Morgan Stanley Research. 17 September; and B. Wang. 2019. Morgan Stanley Models SpaceX Value at \$120+ Billion with Starlink. Next Big Future. 8 November.

62 Comcast. 2020. Comcast Reports 1st Quarter 2020 Results. Investor News Details. 30 April.

63 B. Wang. 2019. SpaceX Starlink Will Equal Launch Revenue in 2020 and Will Make Elon the World's Richest Person by 2023. Next Big Future. 25 May.

64 M. Sheetz. 2020. Morgan Stanley Expects SpaceX Will Be a \$100 Billion Company Thanks to Starlink and Starship. CNBC. 22 October.

65 J. Johnson. 2018. Bandwidth Demand and Decreasing Satellite Costs Will Help Drive the Space Economy. US Chamber of Commerce. 22 October. 
Figure 11: Bandwidth Demand by Application for Geostationary Orbit High-Throughput Satellites in Asia and the Pacific

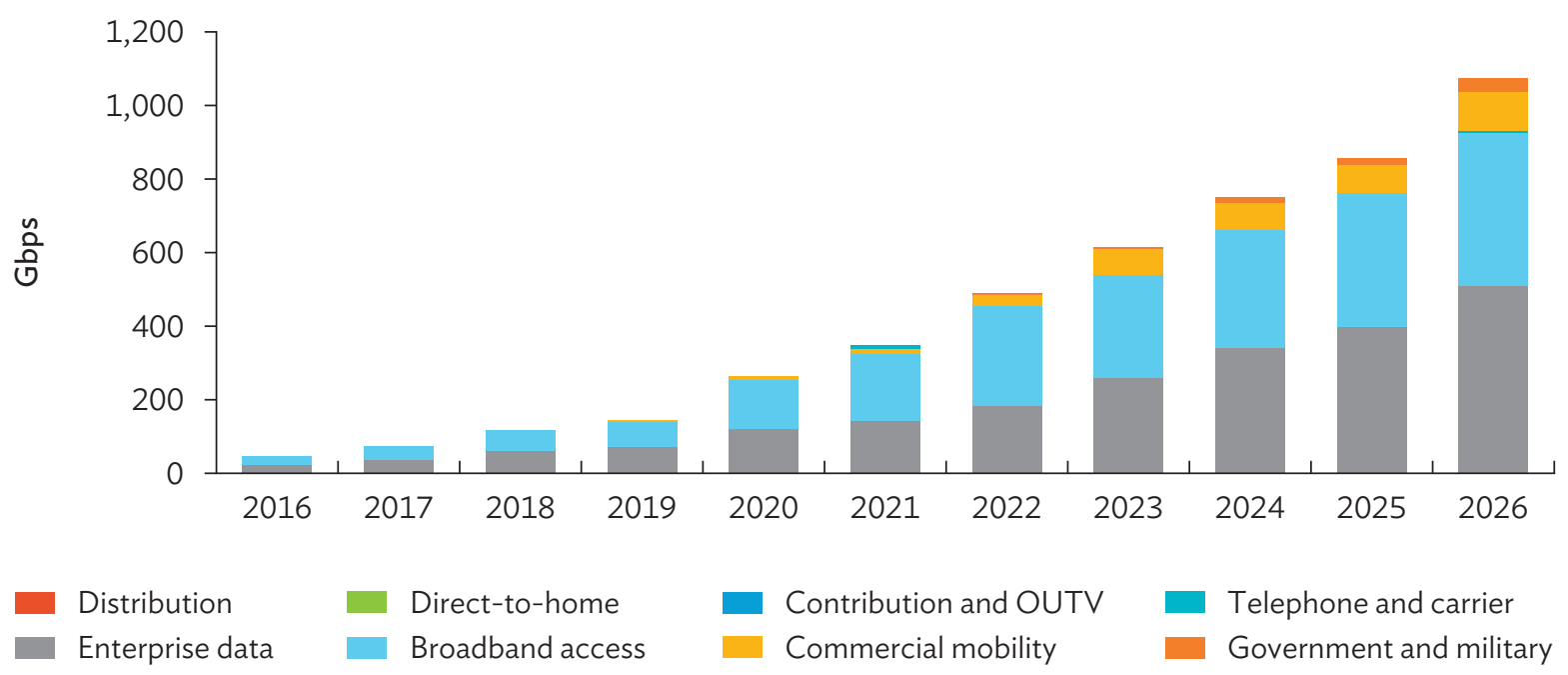

Gbps = gigabits per second, OUTV = occasional-use television.

Source: Northern Sky Research in Asia-Pacific Satellite Communications Council. 2016. Satellite Capacity Supply and Demand in Asia-Pacific. APSCC Quarterly Newsletter. 22(2).

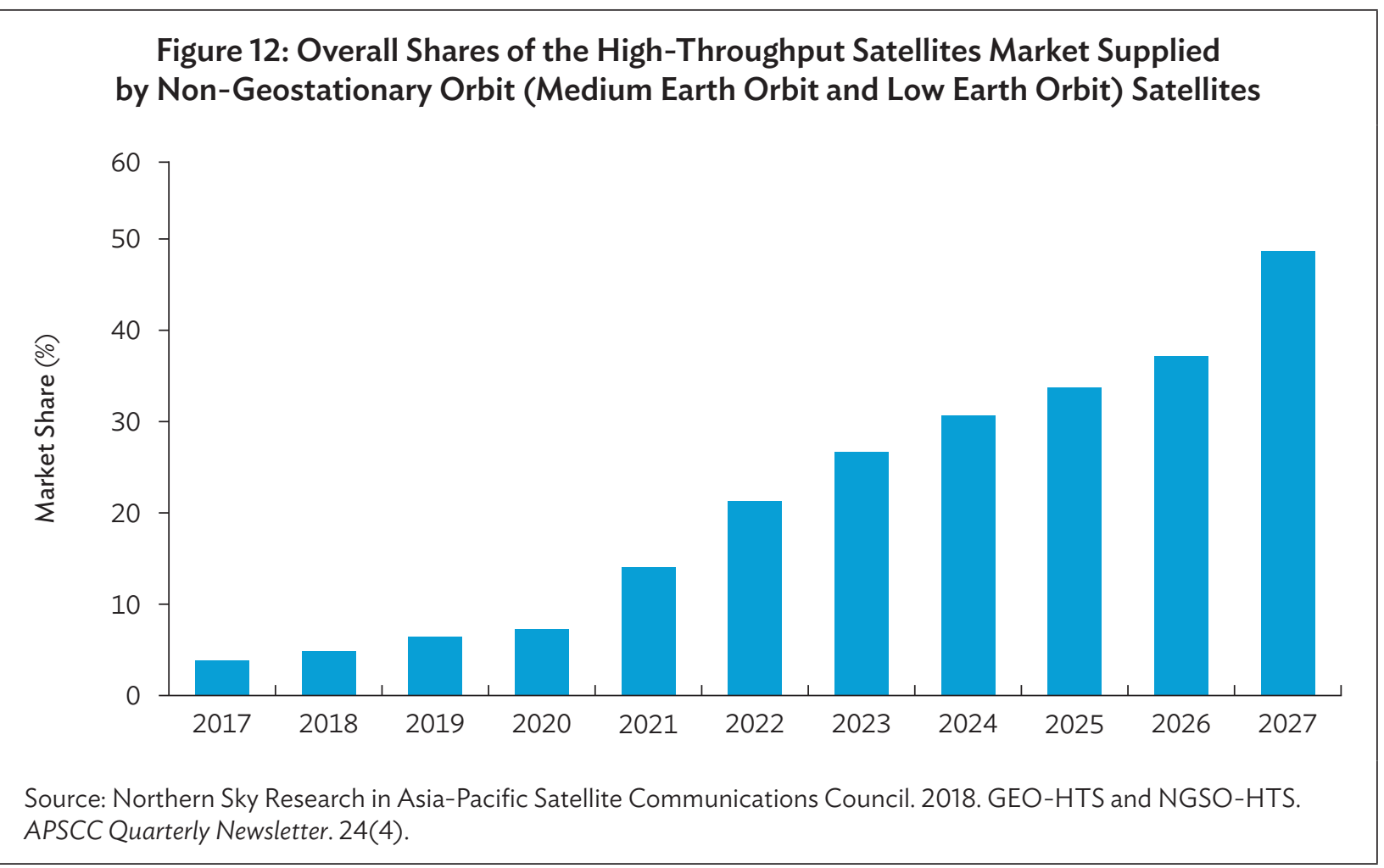


Table 4: Recent National Satellite Deployments in Asia

\begin{tabular}{lcccc}
\hline Country & Satellite & Launch Date & Throughput & Manufacturer \\
\hline Bangladesh & Bangabandhu-1 & Q4 2017/Q12018 & 40 TPEs & Thales Alenia Space \\
\hline PRC & ChinaSat-16 & April 2017 & 25 Gbps & CAST \\
\hline India & GSAT-20 & Q12018 & 70 Gbps & ISRO \\
\hline Indonesia & Palapa-N1 & 2020 & 10 Gbps & CAST \\
\hline Indonesia & Telkom-4 & 2018 & 100 Gbps & SSL \\
\hline Lao PDR & LaoSat-1 & November 2015 & 22 TPEs & CAST \\
\hline
\end{tabular}

Gbps = gigabits per second, Lao PDR = Lao People's Democratic Republic, PRC = People's Republic of China, $Q=$ quarter, $\mathrm{TPE}=$ transponder equivalent.

Source: J. Del Rosario. 2017. Asia \& the Age of High Throughput PrideSats. Northern Sky Research. 10 October.

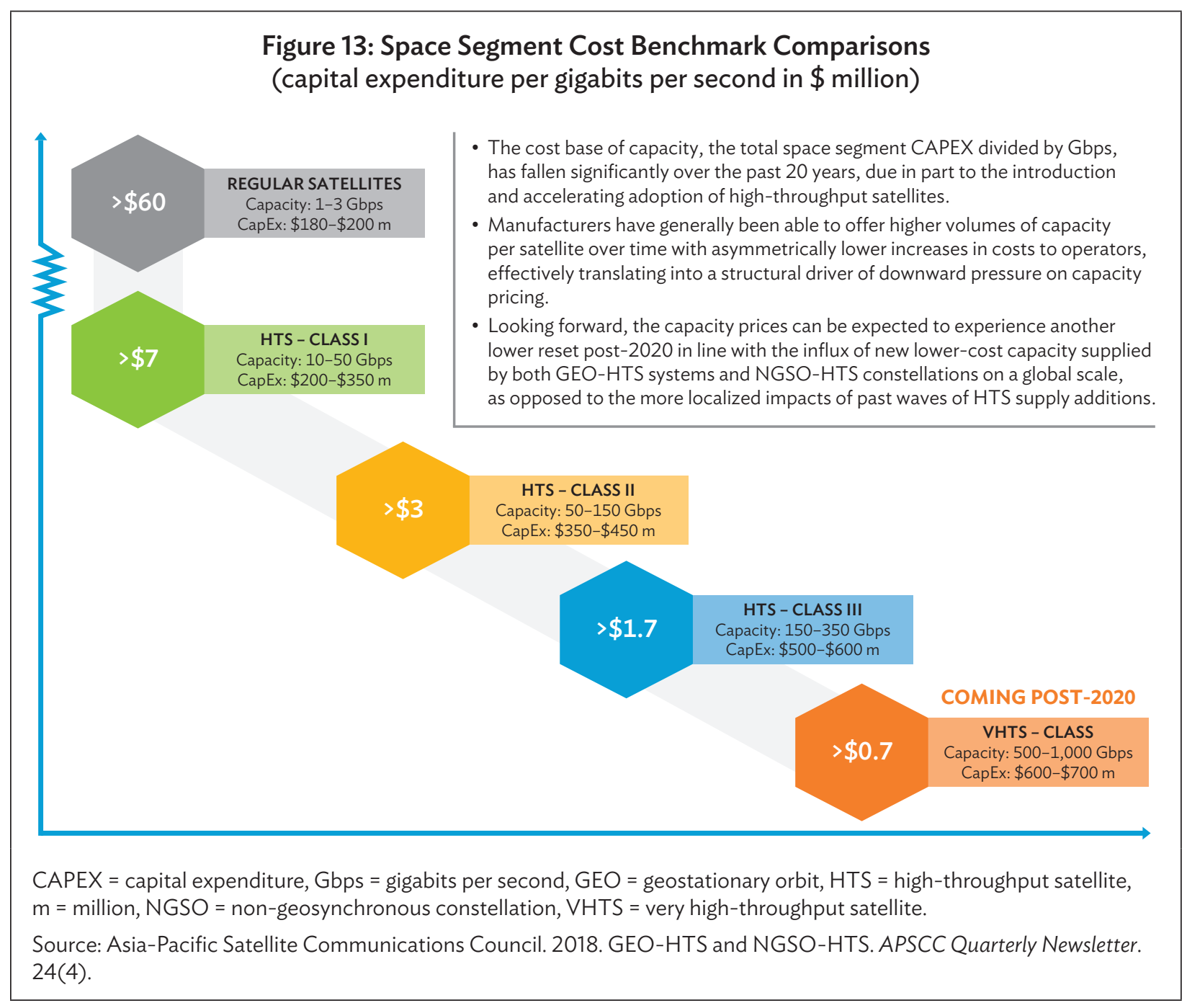




\section{Affordability: price discrimination and community Wi-Fi deployments}

At the current public beta pricing level, Starlink's $\$ 99$ monthly plan is not affordable for many consumers in developing Asia. However, variable pricing by market (at different purchasing price levels) could result in a more affordable service offering. Similarly, community Wi-Fi models could be deployed, such as those being implemented by Hughes/Express Wi-Fi in Indonesia and Latin America where an individual subscription supports time- or data-bound service to potentially hundreds of users consuming small data bundles (in the megabytes) through a publicly accessible Wi-Fi access point. Areas of limited subscriber base may be opportunities for direct or subsidized partnerships.

\section{Complex global networks require various regulatory approvals across countries, technologies, and business segments.}

In the space segment, US-based entities such as Starlink and Project Kuiper require regulatory approval from the FCC as well the ITU. At the 2019 World Radiocommunication Conference, the ITU put into place new rules for non-geostationary orbit (NGSO) constellations to retain spectrum rights. As the ITU has noted: "Under the newly adopted regulatory approach these systems will be required to deploy $10 \%$ of their constellations within 2 years from the end of the current period for bringing into use, 50\% within 5 years, and complete the deployment within 7 years. ${ }^{166}$ In the ground segment, Earth stations or gateways will require technical and business licensing, and service provision to customers will require regulatory approval in every country of operation. How expeditious this process will be depends on the ease of doing business between countries, and the resistance that LEO companies may encounter as they try to enter markets dominated by incumbent operators.

For example, in India, telecom operators are already challenging the expected market entry of NGSO services. In many Asian markets, internet service licensing is restricted by regulators and can be a lengthy process. Interference issues will also have to be addressed if NGSOs interfere with the radio frequency propagation of GEOs. ITU rules are in place to limit power management of radio signals to prevent interference between transmission to and from satellites, as well as other adjustments such as changing frequency bands and reporting beams to avoid interference with GEO beams. The onus is on NGSOs to ensure they are not interfering; otherwise, they will have to shut down problematic assets. ${ }^{67}$

Differences in licensing burdens between countries will impact LEO companies' ability to go to market with a uniform approach. The rules and requirements for internet service providers can be very different from those applying to supply backhaul to local internet service providers, potentially causing a delayed market entry or even a decision to not cover certain countries (Table 5).

\footnotetext{
66 ITU. 2019. ITU World Radiocommunication Conference Adopts New Regulatory Procedures for Non-Geostationary Satellites. Press release. 20 November.

67 V. Cherian. 2019. LEO/GEO Interference: Krato Execs on How to Address This. Satellite ProMe.com. 25 January.
} 
Table 5: Differences in Licensing Requirements for Internet Service Providers across Asia and the Pacific

\begin{tabular}{ll}
\hline Country & \multicolumn{1}{c}{ Licensing } \\
\hline Cambodia & License from telecommunication regulator in Cambodia \\
\hline Indonesia & License from Indonesian Telecommunications Regulatory Authority \\
\hline Japan & $\begin{array}{l}\text { Registration with Ministry of Internal Affairs and Communications (if installing } \\
\text { cable facilities); notification to the said ministry prior to providing telecoms services, } \\
\text { including internet }\end{array}$ \\
\hline Korea, Republic of & Registration with Korea Communications Commission \\
\hline Malaysia & License from Malaysian Communications and Multimedia Commission \\
\hline Philippines & $\begin{array}{l}\text { Telco franchise law passed by Congress; Provisional Authority or Certificate of Public } \\
\text { Convenience and Necessity issued by National Telecommunications Commission }\end{array}$ \\
\hline Singapore & License from Infocomm Media Development Authority \\
\hline Thailand & License from National Broadcasting and Telecommunications Commission \\
\hline
\end{tabular}

Source: Adapted from Table 2.2. by Better Broadband Alliance. 2020. Philippines Digital Economy Report 2020.

Washington, DC: World Bank. p. 41.

\section{Other Risks and Challenges}

Interference with astronomical observation has been cited as a concern with regard to LEO satellites. For example, after initial launches of Starlink satellites in June 2019, the altitude and design of the first satellites resulted in the satellite being visible from Earth with the naked eye. As a result, Starlink adjusted the design in subsequent launches. These are known as "DarkSats," with a darkening coating to make the satellites less visible to stargazers and ground-based observatories. However, issues remain for wide-field sky surveys, particularly at twilight or sunset (with reflection from the sun). For example, $30 \%-40 \%$ of exposures made at some ground observatories around twilight and dawn could be impacted. ${ }^{68}$ Further design and operational adjustments are in progress.

Other concerns have been raised regarding the increase in man-made space objects (space debris), particularly in LEO, which could potentially result in cascading collisions. However, many of the LEO constellations in development include satellites designed for a useful life span of less than half of the 15+ years of GEO satellites (Table 3). Starlink's satellites, for example, are designed to be $100 \%$ demisable and burn up completely once they are put into deorbit at the end of their life span. ${ }^{69}$ Furthermore, LEO constellations are building in mechanisms to track all other objects and avoid collisions. Starlink built an Autonomous Collision Avoidance mechanism into each satellite and uses a US Department of Defense database of debris tracking coupled with the satellite's propulsion system to move the satellites out of collision paths. ${ }^{70}$

68 A. Witze. 2020. How Satellite 'Megaconstellations' will Photobomb Astronomy Images. Nature.com. 26 August.

69 EO Portal. EO Portal Directory. Starlink Satellite Constellation of SpaceX.

70 Starlink. 


\section{RECOMMENDATIONS: WHAT DEVELOPING MEMBER COUNTRIES CAN DO TO LEVERAGE THE OPPORTUNITY PRESENTED BY LOW EARTH ORBIT SATELLITES}

As the new LEO constellations begin offering commercial service in 2021, actions can be taken today to ensure that low- and middle-income countries are well positioned to take advantage of potential costsavings and increased coverage. These include:

Ensure flexible and streamlined licenses procedures for domestic internet service providers and satellite broadband providers.

Licensing regimes of internet service providers differ widely between countries. Good practice licensing policy includes simple registration with administrative bodies, rather than complex and onerous procedures that require legislative approvals. Regimes that require congressionally awarded franchise licenses, for example, create a significant barrier to entry and allow for rent seeking by firms that are able to navigate the cumbersome processes.

\section{Allow for satellite provision of international internet capacity without a requirement for domestic ground stations to route traffic to and from satellite transponders.}

So-called data localization regulations, that require internet traffic within a country to pass through nationally mandated infrastructure points of presence, create barriers to deployment and increase cost and complexity. National requirements, which stipulate that satellite transponder data traffic must transit through a domestic ground station (rather than be allowed to transmit from a ground station located in another country), create burdensome infrastructure deployment requirements. LEO constellation firms may decide that these represent too large a cost for markets with small potential revenue opportunities. It is common for internet traffic to be transmitted via satellite transponders that originate in a country where the satellite's ground station is located, particularly for smaller markets whereby providers need to aggregate total traffic being transmitted to achieve economies of scale.

If future versions of LEO satellites are able to deploy optical inter-satellite links, optical laser beams will directly transmit traffic between satellites in space. This will create further efficiencies in space network segments and could allow satellite constellations to reduce the number of ground stations needed. Regulations that impose a domestic ground station requirement would negate these efficiencies. In cases where the requirements to transmit data locally are driven by sovereignty and cybersecurity justifications, it may be possible to put in place policies that preserve sovereignty and cybersecurity principles without requiring data localization. 


\section{Reduce or remove import tariffs, quotas, or local manufacturing requirements for satellite user terminals.}

Hardware, software, and licensing costs for user terminals (consumer equipment, including satellite antennas, modems, and $\mathrm{Wi}-\mathrm{Fi}$ access points) contribute to the total cost of satellite internet service, and user terminals are already priced significantly above other broadband internet service hardware such as cable modems or stand-alone Wi-Fi access points. Reducing the production cost of user satellite terminals requires mass manufacturing and economies of scale; the benefits of which can best be passed to consumers if trade barriers do not further increase the cost of devices.

\section{Engage in regional discussion and cooperation both in terms of regulatory convergence to improve the "ease of doing business" for LEO satellite connectivity as well as for potential demand aggregation between markets.}

The expansion of satellite coverage and increase in available capacity will particularly benefit countries that have limited international internet bandwidth being supplied by undersea and terrestrial fiber optic cables, such as small island developing states and landlocked developing countries. Regional integration between countries and their neighbors could accelerate deployment timelines by easing the more cumbersome regulatory issues and forging convergence of licensing issues. Similarly, aggregation of demand between markets could present more attractive deployment timeline prioritization and may also generate bargaining power for favorable terms of service.

\section{Deploy universal access funding to support public access through community Wi-Fi deployments.}

Individual subscriptions to LEO service may still be commercially priced at levels beyond the affordability thresholds for low- and middle-income consumers in developing countries. However, public access could be subsidized by national and local governments partially or in full, either one-time or recurring, for the initial hardware and/or trial service, or to provide free public Wi-Fi. A number of countries in Asia and the Pacific fund public access by subsidizing free Wi-Fi services, of which LEO could provide connectivity in remote areas. Public access services via satellite could support connectivity to unconnected and underconnected government offices, schools, hospitals, and other public facilities. Public-private partnerships may be helpful in this regard, both in terms of consumer access as well as upstream infrastructure development (such as ground stations).

Invest in developing accurate, publicly available, mobile coverage and network infrastructure availability maps to better identify geographic areas that are unserved and underserved by current service providers.

Comprehensive, up-to-date, and publicly available (open data) mapping of network infrastructure (mobile cellular base stations, fiber optic cable routes, microwave backhaul lines, points of presence, internet exchange points, and others) as well as service coverage areas will better inform public and private decisions on where to allocate resources and investment to expand service availability. A tool made available by ITU in the regional and national planning is available at https://www.itu.int/itu-d/tndmap-public/. 


\section{Consider supporting consumer financing for user terminals.}

To increase the affordability of user terminals for individual subscriptions, governments could work with consumer finance institutions to develop programs that amortize the cost of user terminals over a service period, reducing the up-front cost barrier to access LEO service.

\section{Support demand generation activities.}

These include enhancing the digital skills of the general public with emphasis on the youth. In addition, technical skill development, such as VSAT deployment and maintenance for remote areas can help not only in connectivity to communities, but also assists in recovery of post-disaster telecommunication. In addition, demand generation could be considered to sustain connectivity. For instance, pacific connectivity and rural connectivity could go with digital applications and services, such as e-commerce, trade, and financial services, so that the community and households will be able to pay. 


\section{REFERENCES}

ADB. 2019. Kacific1 Satellite Launch to Bring Affordable Internet to Remote Parts of Asia and Pacific. News release. 17 December.

Aid and International Development Forum. 2019. Ka vs. Ku Band: Which is the Best for Satellite Broadband? 24 September.

Airbus. 2021. OneWeb Satellites Constellation: Connection for People All over the Globe.

Amazon. 2020a. Amazon Receives FCC Approval for Project Kuiper Satellite Constellation. Amazon News. 30 July.

_. 2020b. Nima Mahanfar Discusses the Science Behind Project Kuiper Customer Terminal Antenna. Amazon Science. 16 December.

Asia-Pacific Satellite Communications Council. 2016. Satellite Capacity Supply and Demand in Asia-Pacific. APSCC Quarterly Newsletter. 22(2).

- 2018. GEO-HTS and NGSO-HTS. APSCC Quarterly Newsletter. 24(4).

Barney, R. 2018. Telesat Says Ideal LEO Constellation is 292 Satellites, But Could Be 512. World Teleport. Org. 11 September.

Baylor, M. 2018. With Block 5, SpaceX to Increase Launch Cadence and Lower Prices. NASA Space Flight. 17 May.

BBC. "Satellites to breach the digital divide." (Minute 11:34).

Better Broadband Alliance. 2020. Philippines Digital Economy Report 2020. Washington, DC: World Bank. p. 41.

Blumenthal, E. 2020. Amazon's Project Kuper Gets FCC Approval for over 3,200 Internet Satellites. CNet. 31 July.

Brown. M. 2020a. SpaceX: Elon Musk Breaks Down the Cost of Reusable Rockets. Inverse. 22 September.

_. 2020b. SpaceX Starlink Beta Test: Coverage Area, Pricing and More. Inverse. 21 July.

Burkitt-Gray, A. 2020. OneWeb Blasts Back Into Action from Russia's Far East. Capacity Media. 18 December.

Burrell, H. 2021. What's Elon Musk's Starlink Doing in New Zealand. The Business Desk. 2 January.

Chaudhary, S. 2020. China Plans to Launch 10,000 Satellites to Compete With Elon Musk's SpaceX. The EurAsian Times. 19 November. 
Cherian, V. 2019. LEO/GEO Interference: Krato Execs on How to Address This. Satellite ProMe.com. 25 January.

Clark, S. 2021. SpaceX Smashes Record with Launch of 143 Small Satellites. Spaceflight Now. 24 January.

Comcast. 2020. Comcast Reports 1st Quarter 2020 Results. Investor News Details. 30 April.

Comms Update. 2021. Starlink pre-ordering in at least 18 countries; keen interest reported in Canada. 15 February.

Connect.Me. https://www.connectme.my/.

Del Portillo, I. et al. 2018. A Technical Comparison of Three Low Earth Orbit Satellite Constellation Systems to Provide Global Broadband. MIT presentation delivered at the 69th International Astronautical Congress. Bremen. 1 October.

Del Rosario, J. 2017a. Asia \& the Age of High Throughput PrideSats. Northern Sky Research. 10 October.

2017b. Pricing the Satellite Markets. National Sky Research. 22 August.

De Selding, P. 2020. Modem / Antenna Designer Satixfy's CEO: OneWeb and SpaceX Starlink are Dreaming. Space Intel Report. 7 October.

EO Portal. Starlink Satellite Constellation of SpaceX. EO Portal Directory. https://directory.eoportal.org/ web/eoportal/satellite-missions/s/starlink.

Euroconsult. 2018. Satellite Communications and Broadcasting Market Survey.

Facebook.com. OneWeb Launch \#5. https://web.facebook.com/watch/live/?v=3796164563794788\&r ef $=$ external\&_rdc $=3 \& \_r d r$.

Forrester, C. 2020. Telesat to Start LEO services in 2022. Advanced Television. 12 October.

2021. Report: Satellite broadband capacity to grow 10x by year-end. Advanced Television. 12 February.

Foust, J. 2021. Lynk to soon begin tests of cellular connectivity using first satellite. SpaceNews. 11 February. Gebhardt, C. 2020. UK Government Acquires OneWeb in Curious Move. NASA Space Flight. 3 July.

Goulding, L. 2020. Untangling the OneWeb Web. London Economics: Space in Focus. Issue No. 3. 27 August.

Government of the United Kingdom. 2020. UK Government to Acquire Cutting-Edge Satellite Network. 3 July. 
Gunter's Space Page. n.d. JCS at 18/Kacific 1. https://space.skyrocket.de/doc_sdat/jcsat-18 _kacific-1.htm\#: :text=The\%20Kacific\%201\%20payload\%20is,ever\%20achieved\%20in\%20the\%20 region.

Hardesty, L. 2021. OneWeb Raises \$400M from SoftBank, Hughes. Fierce Wireless. 15 January.

Harebottle, A. 2018. Will LEO Kickstart the Asian Broadband Market? Via Satellite.

2020. Bandwidth Pricing: How Low Can it Go? Via Satellite. June.

Henry, C. 2018a. EchoStar Buys Jupiter-3 “Ultra High Density Satellite” from SSL. Space News. 9 August.

2018b. SES, With FCC's Blessing, Says O3b Constellation Can Reach Global Coverage. Space News. 9 June.

- 2019a. Kacific, With SpaceX Launch Imminent, Borrows $\$ 160$ Million for Satellite Refinancing. Space News. 6 December.

2019b. SpaceX Submits Paperwork for 30,000 more Starlink Satellites. Space News. 15 October. Holmes, M. 2020. In the Eye of the Storm: Greg Wyler Breaks Cover to Talk OneWeb. Via Satellite.

Howell, E. 2020. The FCC Has Approved Amazon's Plan for its Kuiper Satellite Constellation. Here's What that Means. Space.com. 20 August.

International Telecommunication Union (ITU). 2019a. Facts and Figures 2019: Measuring Digital Development.

2019b. ICT Price Baskets.

-2019c. ICT Statistics: ICT Prices.

_. 2019d. ITU World Radiocommunication Conference Adopts New Regulatory Procedures for Non-Geostationary Satellites. Press release. 20 November.

_.2019e. Measuring Digital Development: ICT Price Trends 2019.

2020a. Connecting Humanity.

2020b. ITU and Kacific Join Forces to Boost Emergency Telecoms and ICT Development in Vanuatu. ITU News. 19 May.

_.2020c. Measuring Digital Development: Facts and Figures 2020.

2020d. The Last-Mile Internet Connectivity Solutions Guide: Sustainable Connectivity Options for Unconnected Sites. 
ITU and UNESCO. 2019. The State of Broadband 2019: Broadband as a Foundation for Sustainable Development.

iTrinegy. n.d. Why is Satellite Latency High?

Johnson, J. 2018. Bandwidth Demand and Decreasing Satellite Costs Will Help Drive the Space Economy. US Chamber of Commerce. 22 October.

Jonas, A. et al. 2019. SpaceX, Starlink, and Tesla: Moving into Orbit? Morgan Stanley Research. 17 September.

Kan, M. 2021. SpaceX Opens Starlink Pre-Orders, But It May Take Months to Arrive. PC Mag Asia.

Louise, N. 2019. Amazon Seeks Permission from FCC to Launch over 3,000 Broadband Internet Satellites for its 'Project Kuiper' Initiative. Tech Startups. 9 July.

Lunden, I. 2021. OneWeb has Now Raised \$1.4B, with \$400M from SoftBank and Hughes, to Help Fund its First Satellite Fleet. Tech Crunch. 15 January.

Mathewson, S. 2021. Arianespace to Launch New Fleet of OneWeb Internet Satellites Tonight. Here's How to Watch. Space.com. 24 March.

Mauldin, A. 2019. Will New Satellites End the Dominance of Submarine Cables. Telegeography Blog. 1 July.

Maxis. Maxis Fibre Broadband. https://www.maxis.com.my/broadband/maxis-fibre/.

Mirandilla-Santos, M. 2020. Digital Divide: Policy and Regulations in DMCs. Better Broadband Alliance presentation. 23 November.

Mohney, D. 2020. SpaceX Has a Lot Riding on Starlink’s \$499 “UFO on a Stick.” Space News. 19 November.

National Aeronautics and Space Administration Global Change Master Directory. n.d. Orbit. https://web.archive.org/web/20100527132541/http:/gcmd.nasa.gov/User/suppguide/platforms/orbit. html.

O'Callaghan, J. 2020. Europe Wants to Build Its Own Satellite Mega Constellation to Rival SpaceX's Starlink. Forbes. 23 December.

OneWeb. https://onewebsatellites.com/.

2020. OneWeb Files for Chapter 11 Restructuring to Execute Sale Process. 27 March.

Palerm, L. 2019. Price Optimization for Satellite Backhaul. Northern Sky Research. 2 July.

Ralph, E. 2019. SpaceX Announces Second Starlink Satellite Launch in Two Weeks. Teslarati.com. 10 December. 
Reddit.com. 2020a. 21st Century Vehicles of Human Spaceflight.

2020b. Starship vs. Crew Dragon.

SatBeams. 2020. List of Satellites at Geostationary Orbit.

Satellite Signals. 2020. Internet VSAT Access via Satellite: Costs.

Sheetz, M. 2020. Morgan Stanley Expects SpaceX will be a $\$ 100$ Billion Company Thanks to Starlink and Starship. CNBC. 22 October.

Shepardson, D. 2020. FCC Awards \$9.2 Billion to Deploy Broadband to 5.2 Million U.S. Homes, Businesses. Reuters.com. 8 December.

Shotwell, G. 2018. SpaceX's Plan to Fly You Across the Globe in 30 Minutes. Speech delivered for TedTalks on 14 May.

Smith, R. 2020. How Much Cheaper are SpaceX Reusable Rockets? Now We Know. MSN Money. 10 May.

SpaceX. n.d. Capabilities and Services.

_. Starlink Mission. Youtube.

Starlink. https://www.starlink.com/.

TASS Russian News Agency. 2018. Russia to Create Orbital Internet Satellite Cluster by 2025. 22 May.

Tech Portal. 2020. Amazon to Invest \$10Bn on its SpaceX Starlink Competitor, 'Project Kuiper.' 31 July.

Telegeography Blog. 2020. Submarine Cable 101.

Telesat. 2018. Telesat Signs Airbus Defence and Space to Further Develop the Design for Telesat's Global LEO Satellite Constellation. 1 August.

- 2021. Telesat to Redefine Global Broadband Connectivity with Telesat Lightspeed, the World's Most Advanced Low Earth Orbit (LEO) Satellite Network. Press release. 9 February.

UNESCAP. 2019. Satellite Communications in Pacific Island Countries.

United Nations. 2020. Policy Brief: Education during COVID-10 and beyond.

Viasat. 2018. Viasat Announces Highest-Speed, Unlimited Satellite Internet Service - Nationwide. Cision PR Newswire. 27 February.

Wainscott-Sargent, A. 2019. LEO Advances on the Ground. Via Satellite. 
Wang, B. 2019a. Morgan Stanley Models SpaceX Value at $\$ 120+$ Billion with Starlink. Next Big Future. 8 November.

2019b. SpaceX Starlink Will Equal Launch Revenue in 2020 and Will Make Elon the World's Richest Person by 2023. Next Big Future. 25 May.

Wattles, J. 2020. Softbank-Backed Satellite Startup OneWeb files for Bankruptcy. CNN Business. 28 March.

Wendel, J. 2020. SpaceX CEO Elon Musk Explains Why We Need a 'Whole New Architecture' for Space Travel. Space.com. 10 March.

Witze, A. 2020. How Satellite 'Megaconstellations' will Photobomb Astronomy Images. Nature.com. 26 August.

World Bank. 2019. Innovative Business Models for Expanding Fiber-Optic Networks and Closing the Access Gaps. 


\section{Digital Connectivity and Low Earth Orbit Satellite Constellations}

Opportunities for Asia and the Pacific

Satellite communication plays an important role in the global connectivity ecosystem. It connects rural and remote populations, provides backhaul connectivity to mobile cellular networks, and enables rapid communications for emergency and disaster responses. Low Earth orbit constellations may prove to be transformational to the connectivity landscape based on their global coverage and their suitability for areas not served by fiber optic cable networks. The Asian Development Bank's developing member countries are well placed to benefit from this expansion of internet connectivity. It will be particularly valuable for small island developing states and landlocked developing countries with limited international bandwidth internet.

\section{About the Asian Development Bank}

ADB is committed to achieving a prosperous, inclusive, resilient, and sustainable Asia and the Pacific, while sustaining its efforts to eradicate extreme poverty. Established in 1966, it is owned by 68 members -49 from the region. Its main instruments for helping its developing member countries are policy dialogue, loans, equity investments, guarantees, grants, and technical assistance. 